\title{
Dissecting Aggregate Real Wage Fluctuations: Individual Wage Growth and the Composition Effect
}

\author{
Mary C. Daly \\ Federal Reserve Bank of San Francisco \\ Bart Hobijn \\ Federal Reserve Bank of San Francisco, \\ VU University Amsterdam and Tinbergen Institute \\ Theodore S. Wiles \\ The Analysis Group
}

May 2012

Working Paper 2011-23

http://www.frbsf.org/publications/economics/papers/2011/wp11-23bk.pdf

The views in this paper are solely the responsibility of the authors and should not be interpreted as reflecting the views of the Federal Reserve Bank of San Francisco or the Board of Governors of the Federal Reserve System. 


\title{
Dissecting Aggregate Real Wage Fluctuations: Individual Wage Growth and the Composition Effect
}

\author{
MARY C. DALY \\ Federal Reserve Bank of San Francisco ${ }^{1}$

\section{BART HOBIJN} \\ Federal Reserve Bank of San Francisco, \\ VU University Amsterdam, \\ and Tinbergen Institute
}

\author{
THEODORE S. WILES \\ The Analysis Group
}

May 16, 2012

\begin{abstract}
Using data from the Current Population Survey from 1980 through 2011 we examine what drives the variation and cyclicality of the growth rate of real wages over time. We employ a novel decomposition technique that allows us to divide the time series for median weekly earnings growth into the part associated with the wage growth of persons employed at the beginning and end of the period (the wage growth effect) and the part associated with changes in the composition of earners (the composition effect). The relative importance of these two effects varies widely over the business cycle. When the labor market is tight job switchers get large wage increases, making them account for half of the variation in median weekly earnings growth over our sample. Their wage growth, as well as that of job-stayers, is procyclical. During labor market downturns, this procyclicality is largely offset by the change in the composition of the workforce, leading aggregate real wages to be almost non-cyclical. Most of this composition effect works through the part-time employment margin. Remarkably, the unemployment margin neither accounts for much of the variation in nor much of the cyclicality of median weekly earnings growth.
\end{abstract}

Keywords: Business cycle, labor market dynamics, wage growth.

JEL-codes: E24, J3, J6.

\footnotetext{
1 We are grateful to Alessandro Barbarino, Marianne Bitler, Michael Elsby, Thomas Lemieux, Ayşegül Şahin, Eric Swanson, and seminar participants at the New York, St. Louis, and San Francisco Federal Reserve Banks, the NBER Labor Studies group, the Riksbank, OECD, and Tinbergen Institute for useful suggestions and comments. The views expressed in this paper solely reflect those of the authors and not necessarily those of the Federal Reserve Bank of San Francisco, nor those of the Federal Reserve System as a whole. Corresponding author: Bart Hobijn, bart.hobijn@sf.frb.org.
} 
Dissecting Aggregate Real Wage Fluctuations

\section{Introduction}

The muted and inconsistent fluctuations of aggregate real wage growth have been a perennial puzzle of macroeconomics. Aggregate real wages exhibit less variability over time than most macroeconomic models predict and movements that do take place appear only modestly related to the business cycle. ${ }^{2}$ Both of these patterns are apparent in Figure 1 which plots the growth in real median weekly earnings along with the unemployment rate.

As the figure shows, aggregate real wage growth varies much less than the unemployment rate, a standard measure of business cycle movements. ${ }^{3}$ In addition, and in contrast to most models, there is no apparent single pattern of comovement between wage growth and the unemployment rate over time. ${ }^{4}$ For example, in the 1980s aggregate real wage growth looks slightly procylical, falling during the deep recessions of the first part of the decade and rising when the unemployment rate declined in middle of the decade. From the late 1980's through the mid 1990's, real wage growth appears countercyclical, increasing at the same time that the unemployment rate rose. The relationship between real wage growth and unemployment seemed to vanish altogether during the second half of the 1990s as the unemployment rate hovered near its structural level and wages grew rapidly, statistically producing an acyclical relationship. Finally, in the most recent severe recession, real wage growth remained high while unemployment increased, suggesting that aggregate real wages responded countercyclically.

In contrast to the movements of aggregate real wage growth, real wage fluctuations of individuals consistently have been found to be procyclical, rising as the unemployment rate falls and falling as the unemployment rate rises. Moreover, in keeping with standard macro theory, the size of the response is non-trivial. For example, several authors including Bils (1985), Solon, Barsky, and Parker (1994), and Devereux, (2001) find that a one percent increase in the

\footnotetext{
${ }^{2}$ Several authors have concluded that wages are modestly tied to business cycle conditions: for example, Lucas (1977); Mankiw (1989); and Christiano and Eichenbaum (1992). See Abraham and Haltiwanger (1995) for a survey of empirical studies of realwage growth over the business cycle.

${ }^{3}$ The limited variability of aggregate real wage growth fails the predictions of a variety of macro models including real business cycle models (Hansen 1985) and models of frictional unemployment (Shimer 2005). The flipside of this is that unemployment, employment, and hours tend to move more than these models predict, suggesting that most of the adjustments in the labor market come through quantities rather than prices.

${ }^{4}$ While most models expect wages to exhibit some cyclicality the direction depends on the model. For example, Kydland and Prescott (1982), Barro and King (1984), Rotemberg and Woodford (1992), and Bartelsman et al (1994) all posit procyclical real wages while a countercyclical relationship is predicted by Keynesian with sticky wages. See Swanson (2007) for a brief review of these issues.
} 
unemployment rate reduces real-wage growth of individuals by about 1.3 percentage points. This pattern holds across decades and for various subpopulations of the labor market.

To reconcile the different views coming from aggregate and individual real wage fluctuations researchers have noted that movements in aggregate real wages reflect the net result of two separate effects. The first, which we will term the wage growth effect, captures the responsiveness of individual wages, or, wages of comparable worker groups, to fluctuations in the economy. In simple terms, if a rising tide lifts all boats, the wage growth effect measures by how much (Hines, Hoynes, and Krueger 2001). The size of the wage growth effect at any point in the business cycle is determined by the efficiency of markets, which is itself determined by wage setting practices, wage norms, and government policy. Efficiency wage models, implicit contract models, and insideroutsider models as well as the long literature on nominal wage rigidities all focus on understanding the wage growth effect. ${ }^{5}$ Models of wage bargaining have frequently been used to explain why aggregate wages adjust much less than employment or hours; nominal rigidities are pointed to as a reason for limited cyclical responsiveness of wages in downturns.

The second effect, termed the composition effect, denotes the impact that changes in the composition of the workforce over the business cycle can have on aggregate wage fluctuations. If hiring or layoffs are not randomly distributed across all types of workers, composition bias can obscure the true relationship between wages and economic conditions. Returning to the boats metaphor, this is the idea that in economic downturns some boats sink; the composition effect measures the impact of the sinking boats on aggregate real wage movements. Previous studies have shown that employment losses during economic downturns disproportionately occur workers with lower than average wages (Hines, Hoynes, and Krueger, 2001, for example). This "upskilling" implies less variation in aggregate real wages than would be implied by models where workers are homogeneous and wages adjust uniformly (Altonji and Devereux, 2000). Research has shown that controlling for composition bias, wages are highly procyclical. ${ }^{6}$

Although these micro studies indicate that aggregate real wage growth reflects both wage growth and composition components and that controlling for composition bias makes wages much

\footnotetext{
${ }^{5}$ Empirical research has focused on nominal wage rigidities (e.g. Card and Hyslop, 1997, Lebow, Saks, and Wilson, 2003, Dickens et al., 2007, and Barratieri, Basu, and Gottschalk, 2010) as well as the relative size of wage fluctuations for job-stayers and jobswitchers (e.g. Bils, 1985, Devereux, 2001). See Pissarides (2009) and Kudlyak (2010) for two useful overviews.

${ }^{6}$ Perry (1972), Bils (1985), and Solon, Barsky, and Parker (1994).
} 
more procyclical, variation in data used, years analyzed, and methods applied have made it difficult for the micro evidence to fully illuminate the drivers of aggregate real wages over time and whether their contributions change over the business cycle. ${ }^{7}$ As such, most modern macro theory continues to struggle with the challenges of the data presented in Figure 1-small and inconsistent responsiveness of wages to the business cycle.

In this context, the aim of our paper is to provide a unified framework in which to examine how the wage growth and composition effects have interacted over time to produce the aggregate real wage fluctuations shown in Figure 1. Our paper develops a strategy for netting out these effects and tracking their importance over time for both the variance of aggregate real wage growth and for aggregate real wage cyclicality. The findings are revealing and provide useful guidance for thinking about how macroeconomic fluctuations affect aggregate real wage growth.

The key conclusions are as follows. The relative importance of the wage growth and composition effects varies considerably over the business cycle. The wage growth effect is strongly procyclical and accounts for the bulk of the variance of real wage growth over time; the wage growth effect is dominated by changes in wages among job switchers. In business cycle downturns, the composition effect rises in importance, offsetting more than half of the procyclicality of the wage growth effect. Much of the composition effect comes through the part-time employment margin. This was especially important in during the Great Recession. Somewhat surprisingly, given its central placement in a variety of macroeconomic models of wage fluctuations, the unemployment margin is relatively unimportant for the variance and cyclicality of real wage growth.

The remainder of the paper is structured as follows. In Section 2 we describe the data we use: the Current Population Survey (CPS) for 1980 through 2011. In Section 3 we introduce a novel percentile decomposition technique that allows us to decompose the change in median wages into tractable components while avoiding issues of top coding present in most publically available individual-level data on earnings in the U.S. ${ }^{8}$ We then show how this technique allows us to focus on movements in the earnings distribution related to different groups (those who enter and exit the workforce and those who stay employed) and to specifically identify the relative contributions of

\footnotetext{
${ }^{7}$ Another reason for this is that most of the empirical work has focused on tying down one aspect of the puzzle (e.g., wage growth of particular groups, composition bias) or been restricted to aggregate or individual data with little ability to reconcile the two pieces.

${ }^{8}$ Our decomposition is closely related to, but different from, the one introduced in DiNardo, Fortin, and Lemieux (1996).
} 
the composition and wage growth effects that drive changes in each of the percentiles of the earnings distribution. In Section 4, we present the results of our decomposition of real median weekly earnings growth in the U.S. from 1980 through 2011. We conclude with Section 5. Two appendices follow: one with the details on the CPS data and the other detailing the mathematical derivations of our percentile decomposition.

\section{Studying Wage Growth using the Current Population Survey}

For our analysis we use data from the Current Population Survey (CPS). The CPS is uniquely suited to our project since it is the only publically available, long-standing, nationally representative, high-frequency, micro data source on labor market status and earnings for the U.S. It also has the important advantage of being a key source of information on aggregate U.S. wage growth. ${ }^{9}$ The most commonly quoted aggregate measure of wages derived from the CPS, and the one we focus on in our analysis, is Median Usual Weekly Earnings (MWE) of full-time wage and salary workers. ${ }^{10}$ MWE is published at a quarterly frequency. Usual Weekly Earnings are defined as “...earnings before taxes and other deductions and include any overtime pay, commissions, or tips usually received (at the main job in the case of multiple jobholders)." 11

To show how the CPS data on aggregate real wage growth compares with alternative aggregate wage measures, especially those used in other empirical studies, Figure 2 plots Average Hourly Earnings (AHE) of production and non-supervisory workers in the private sector, Compensation Per Hour $(\mathrm{CPH})$ in the nonfarm business sector, and the Employment Cost Index (ECI) along with

\footnotetext{
${ }^{9}$ Previous research on the drivers of aggregate wage dynamics relied on smaller panel surveys which provide detailed data on individuals. For example, Bils (1985) uses the National Longitudinal Survey of Youth (NLS/Y). Solon, Barsky, and Parker (1994), Devereux (2001), and Hagedorn and Manovskii (2010) use the Panel Study of Income Dynamics (PSID). Gertler and Trigari (2009), Barattieri, Basu, and Gottschalk (2010) use data from the Survey of Income and Program Participation (SIPP). Card and Hyslop (1997), like we do here, use data from the Current Population Survey (CPS).

${ }^{10}$ The focus on full-time wage earners still means that MWE is affected by fluctuations in overtime, overtime pay, as well as a trend in the average work week for full-time workers (See Perry, 1972, for a discussion of these issues)

${ }^{11}$ The CPS survey questions related to usual weekly earnings have evolved over time: "Prior to 1994, respondents were asked how much they usually earned per week. Since January 1994, respondents have been asked to identify the easiest way for them to report earnings (hourly, weekly, biweekly, twice monthly, monthly, annually, other) and how much they usually earn in the reported time period. Earnings reported on a basis other than weekly are converted to a weekly equivalent. The term "usual" is as perceived by the respondent. If the respondent asks for a definition of usual, interviewers are instructed to define the term as more than half the weeks worked during the past 4 or 5 months" (BLS, 2011).
} 
MWE from the CPS from 1980 through 2011. ${ }^{12}$ All measures of nominal wages are deflated by the Personal Consumption Expenditures Price Index so that the figure shows growth in real wages.

As the figure shows, all of these measures are highly correlated and exhibit similar cyclical patterns. The correlation of real wage growth measured by MWE with the other three measures is 0.6 or higher. Importantly for our work the MWE series appears to capture the coincident movements of the competing series very well. Visual inspection shows that MWE is rarely an outlier across the series in terms of fluctuations in growth. ${ }^{13}$ Of the four measures of real wage growth in Figure 2, MWE, which is based on the CPS, is the only one for which underlying individual level data is available that covers both the level of earnings of workers as well as their labor market status.

The micro data underlying the CPS aggregates can be used cross-sectionally or, with some effort, to construct short panels of individual respondents. To explain the type of information contained in each of these short panels it is necessary to briefly review the CPS survey design and interview structure. The CPS is a dwelling-based survey in which households are included for 16 months. Over this period, individuals are interviewed monthly for the first four months, not interviewed for the next eight months, and then interviewed monthly again for the remaining four months before being retired from the sample. ${ }^{14}$ As such, we have eight monthly surveys for each member of our panel.

The CPS survey and interview structure are illustrated in Table 1 (rows 1-2). The regular monthly surveys collect very basic information about labor market status but no information about earnings. Earnings information along with other details of jobs are collected twice during the CPS survey interval, once in survey month 4 (interview month 4) and again in survey month 16 (interview month 8) (Table 1, rows 3-4). ${ }^{15}$ Earnings and job information are collected only for individuals who are employed at the time of the interview. Following other researchers, we rely most heavily on the information collected in these survey months and use the additional information

\footnotetext{
${ }^{12}$ For example, Gertler and Trigari (2009) focus on AHE for the empirical analysis in their paper while Gali (2011) focuses on CPH for his estimate of the New-Keynesian Wage Phillips Curve. Lebow, Saks, and Wilson (2003) analyze the National Compensation Survey data on which the ECI is based.

${ }^{13}$ The exception to this statement is 1994, when MWE rose much more rapidly than the other series. This coincides with the CPS redesign and the way the survey was changed to determine whether someone is a part-time or full-time employee.

${ }^{14}$ Because the CPS is a dwelling-based survey, individuals who change residences are dropped from the sample.

${ }^{15}$ Survey months 4 and 16 (interview months 4 and 8) are commonly referred to as the outgoing rotation groups since they are individuals temporarily moving off the sample frame or permanently retiring from the survey. The matched samples of these outgoing rotation groups are known as the MORG files.
} 
collected in other survey months to refine our labor market status measures as described below. To match individuals across surveys we follow Madrian and Lefgren (1999) and Nekarda (2009). The details are provided in Appendix A. ${ }^{16}$

In any quarter, the published aggregate MWE statistic is based on respondents who are either in the fourth or eighth month of the CPS survey tenure (see Table 1). This means that the 4-quarter growth rate of published MWE is based on a changing sample of individuals. To consider wage changes of a group of individuals, we instead need a matched sample for our analysis. Using the short individual panels, we compute an aggregate "Matched MWE". This "Matched MWE" measures the growth in median wages for those individuals who are in survey month 16 and were in survey month 4 a year ago. Figure 3 plots our matched MWE against the published aggregate, shown earlier in Figures 1 and 2. The two measures of MWE are very similar with a correlation of 0.79. As such, we conclude that the measure of MWE growth we use for our decomposition has the same main characteristics of interest as the published MWE growth. Our data cover 1980 through 2011. ${ }^{17}$

\section{Subgroups used in decomposition}

Having settled on a wage series, we next turn to organizing our data into groups relevant for the decomposition. Since our goal is to understand which labor market groups drive fluctuations in aggregate real wages we divide individuals based on reported labor market status in survey months 4 and 16 (interview months 4 and 8). We are able to distinguish five distinct states: (1) full-time employed in the same job in both periods, (2) full-time employed in a different job from one period to the next, and (3), (4), and (5) transitions to or from part-time employment, unemployment, or not in the labor force, respectively. ${ }^{18}$ See Table 2 for a visual accounting of these groups.

\footnotetext{
${ }^{16}$ One concern about using the CPS to track individuals over time is that the sample may not be representative of the population. Since the CPS is a housing unit survey, when individuals change residences they are dropped from the sample and the new occupants of the unit are interviewed. While this does not alter the cross-sectional representativeness of the CPS, it can potentially interfere with representativeness of the individual-based short panels, especially if moving is related to the variables being analyzed. However, work by Nekarda (2009) and Kim (2009) which carefully corrects for this type of sample attrition finds that the biases introduced are empirically modest. Thus, we use the raw CPS matched data as our baseline for analysis.

${ }^{17}$ Due to the scrambling by the Census Bureau of identifiers that we use to match individuals across months, we are unable to perform this matching for two sub-periods of our sample, namely October 1985 through September 1986 and September 1995 through August 1996.

${ }^{18}$ We do not differentiate between individuals in any of these subgroups based on their observable characteristics. Hence, our composition effect is not measured based on efficiency units, as is done in Bowlus, Liu, and Robinson (2002). They, however, do not aim to decompose aggregate wage fluctuations but focus on the sensitivity of parameter estimates to composition bias.
} 
Although most of these states can be directly measured from the CPS survey data, we need to make an imputation to fill out the data matrix displayed in Table 2. It regards the fraction of fulltime workers who stay in the same job versus change jobs over the sample. This distinction is important given the evidence that wage growth of persons who remain in the same job is less cyclical than that of persons who switch jobs. See, for example, Bils (1994), Devereux (2001), Martins, Solon, and Thomas (2010), and Hagedorn and Manovskii (2010). To impute the fraction of full-time employed individuals who stay in the same job we use the methods developed and used by Card and Hyslop (1997), Fallick and Fleischman (2004), and Nagypál (2008). We provide full details of our imputation in Appendix A.

\section{Subgroups as share of full-time wage and salary earners}

The final columns of Table 2 report the average shares (1980-2011) of wage earners who are in each of our five categories at the beginning and end of the period (survey months 4 and 16; interview months 4 and 8). The vast majority (over 89 percent) of wage earners are full-time employed at both the beginning and the end of our individual sample frame. About 40 percent of workers in our sample are full-time employed in the same job; about 49 percent are full-time employed but in different jobs in the first and second periods. Of the remaining wage earners, 2.7 percent of full-time employed at the beginning of the year end up unemployed at the end of it. Conversely, 2.6 percent of those full-time employed at the end of the year were unemployed at the beginning. There are slightly larger numbers of workers moving in and out of the labor market and into or out of part-time or self-employment to or from full-time employment.

\section{Earnings levels of subgroups}

The fact that continuously full-time employed workers account for, on average, about 90 percent of all wage earners suggests that they are likely to drive most of the movements in aggregate wages. In our nomenclature this would suggest that aggregate real wage fluctuations are largely determined by the wage growth effect. However, as previous researchers have noted, during periods of labor market upheaval, such as recessions and recoveries, those exiting from (entering into) full-time employment might also influence movements in aggregate wages, even though on average they make up only a small share of overall wage earners. To show the potential of this type of effect we examine from where in the wage distribution flows into and out of full-time employment are 
typically drawn. Specifically, we consider the share of each of our five labor market status groups that comes from below the median wage computed across all workers. The results are reported in Table 3.

Looking first at the margin most commonly associated with the composition effect (transitions into and out of unemployment), the data show that on average about 64.0 percent of full-time workers who become unemployed were making less than median earnings before entering unemployment (Row 4, Column I). An even larger fraction (72.8 percent) of those making the reverse transition, from unemployment to full-time employment, make below median earnings (Row 4, Column II). The difference between the 64.0 and 72.8 percent in part reflects that the displacement penalty associated with unemployment spells, documented by Farber (1997, 2005).

Row 4 of Table 3 shows that, on average, the incidence of unemployment occurs disproportionately below median earnings. As a result, if unemployment goes up, workers making below median earnings lose their jobs in greater numbers than other workers. Holding wages of other workers constant, this change in the composition of the workforce serves to increase median aggregate wages. This is one example of the composition effect.

The part-time and self-employed (Row 3 of Table 3) as well as those who move into and out of the labor force (Row 5) contribute to the composition effect in a similar way. Most of their flows into and out of full-time employment occur below the median. Thus, when exits from full-time employment to part-time employment or self-employment and not-in-the-labor-force increase, median aggregate wages tend to rise. Finally, it is worth noting that since wages for those in the same job and NISJ (Rows 1 and 2) tend to grow over time, fewer of them earn below the median at the end of the period than at the beginning.

These results illustrate the potential for both wage growth and composition effects to matter for aggregate real wage growth. To accurately quantify the importance of these effects and track their relative contributions over time we need a more formal accounting strategy that allows for a flexible decomposition of aggregate wage movements into component parts. We turn to this in the next section. 
Dissecting Aggregate Real Wage Fluctuations

\section{Wage Growth and Composition Effects: Percentile decomposition}

Decompositions of movements in economic aggregates are commonly used to quantify the various influences on these aggregates. The most common type of decomposition is a shift-share analysis which can be easily applied when the aggregate being examined is a mean. ${ }^{19}$ We, however, are interested in decomposing the growth rate (log change) of the median of the wage distribution; as such, we cannot apply a conventional type of shift-share analysis. As an alternative, we introduce a percentile decomposition that functions like a conventional shift-share analysis but works with distribution functions rather than means.

Our percentile decomposition is similar in spirit to the one introduced by DiNardo, Fortin, and Lemieux (1996). Our method differs in that it does not require the calculation of counterfactual percentiles. Instead, it relies on the application of the mean-value theorem to translate shifts in the distribution function into shifts in percentiles. This difference makes our method more directly comparable to a conventional shift-share analysis as well as somewhat easier to implement than DiNardo, Fortin, and Lemieux (1996). The difference between the two methodologies is explained in detail in Appendix B.

We introduce our decomposition in three steps. First, we illustrate how changes in percentiles are related to shifts in the underlying distribution function. Second, we show that changes in the distribution function can be decomposed into separate parts which in our case map to the composition and wage growth effects we are interested in. We conclude the section with a discussion of how we implement the decomposition to track the dynamics of MWE growth.

\section{Relating changes in percentiles to changes in distribution functions}

To understand how our percentile decomposition follows and differs from the traditional shiftshare analysis it is useful to refer to Figure 4. The figure plots two log-earnings distribution functions, $F(W)$ and $G(W)$. The $p$-th percentiles associated with these two distribution functions are given by $w_{p}$ and $w_{p}^{\prime}$ respectively. To illustrate the relationship between changes in percentiles and changes in the underlying distribution functions we assume, without loss of generality, that

\footnotetext{
${ }^{19}$ See Juhn and Potter (2006) for an example related to the labor force participation rate and Bartelsman, Haltiwanger, and Scarpetta (2004) for an application to labor productivity growth.
} 
there is positive growth in the percentile over the period and that $w_{p}^{\prime}>w_{p}$. These percentiles satisfy

$$
p=F\left(w_{p}\right)=G\left(w_{p}^{\prime}\right)
$$

Our decomposition works as follows. We apply a shift-share type decomposition to the changes in the distribution functions. That is we decompose $F\left(w_{p}^{\prime}\right)-F\left(w_{p}\right)$ and $G\left(w_{p}^{\prime}\right)-G\left(w_{p}\right)$ into contributions by the different groups we identify. We then apply the mean value theorem to translate these contributions, measured along the vertical axis in Figure 4, into changes in earnings along the horizontal axis, i.e. $w_{p}^{\prime}-w_{p}$. This is what yields the decomposition of the change in the percentile of log earnings.

As we show in Appendix B, rearranging (1) allows us to write

$$
\left(F\left(w_{p}^{\prime}\right)-F\left(w_{p}\right)\right)+\left(G\left(w_{p}^{\prime}\right)-G\left(w_{p}\right)\right)=\left(F\left(w_{p}\right)-G\left(w_{p}\right)\right)+\left(F\left(w_{p}^{\prime}\right)-G\left(w_{p}^{\prime}\right)\right)
$$

This result implies that the sum of the changes in each of the distribution functions evaluated between $w_{p}^{\prime}$ and $w_{p}$ equals the sum of the difference in the value of the distribution functions in $w_{p}^{\prime}$ and $w_{p}$. In the figure, the vertical lines $I$ and $I I$ correspond to the left-hand side terms of (2) while the lines $A$ and $B$ correspond to the right-hand side terms.

The left-hand side terms in the above equation can be translated into changes in the percentile by the application of the mean value theorem. If the distribution functions $F(W)$ and $G(W)$ are continuously differentiable, then there exists a $w^{*}$, such that $w_{p} \leq w^{*} \leq w_{p}^{\prime}$, and

$$
\left(F\left(w_{p}^{\prime}\right)-F\left(w_{p}\right)\right)+\left(G\left(w_{p}^{\prime}\right)-G\left(w_{p}\right)\right)=\left[f\left(w^{*}\right)+g\left(w^{*}\right)\right]\left(w_{p}^{\prime}-w_{p}\right) .
$$

This allows us to express the change in the percentile from the beginning to the end of the period, $\left(w_{p}^{\prime}-w_{p}\right)$, in terms of shifts in the distribution function from $F(W)$ to $G(W)$. In particular, we can write

$$
\left(w_{p}^{\prime}-w_{p}\right)=\frac{1}{f\left(w^{*}\right)+g\left(w^{*}\right)}\left\{\left(F\left(w_{p}\right)-G\left(w_{p}\right)\right)+\left(F\left(w_{p}^{\prime}\right)-G\left(w_{p}^{\prime}\right)\right)\right\} .
$$

This generalizes to the case in which the population from which $W$ is drawn is made up of various subgroups. In that case we can apply a shift-share type decomposition to the right-hand side of the above equation. 


\section{Decomposing changes in distribution functions by subgroup}

Equation (1) can be rewritten in terms of conditional distribution functions as

$$
p=\int \varphi(s) F\left(w_{p} \mid s\right) d s=\int \gamma(s) G\left(w_{p}^{\prime} \mid s\right) d s .
$$

As we derive in detail in Appendix B, this can be rearranged to obtain a generalization of equation (2) of the form

$$
\begin{aligned}
& \int \varphi(s)\left\{F\left(w_{p}^{\prime} \mid s\right)-F\left(w_{p} \mid s\right)\right\} d s+\int \gamma(s)\left\{G\left(w_{p}^{\prime} \mid s\right)-G\left(w_{p} \mid s\right)\right\} d s \\
= & \int \varphi(s)\left\{F\left(w_{p} \mid s\right)-G\left(w_{p} \mid s\right)\right\} d s+\int \gamma(s)\left\{F\left(w_{p}^{\prime} \mid s\right)-G\left(w_{p}^{\prime} \mid s\right)\right\} d s \\
& -\int\left[\left\{F\left(w_{p}^{\prime} \mid s\right)-p\right\}+\left\{G\left(w_{p} \mid s\right)-p\right\}\right]\{\gamma(s)-\varphi(s)\} d s .
\end{aligned}
$$

Similar to equation (2), the left-hand side of the above equation is expressed in terms of the changes in each of the conditional distribution functions evaluated between $w_{p}^{\prime}$ and $w_{p}$. The first two terms on the right-hand side of (6) are similar those on the right-hand side of (2) in that they reflect changes in the distribution functions at $w_{p}^{\prime}$ and $w_{p}$. The final term on the right-hand side captures the effect of the changes in the shares of the different sub-groups.

Just like in the example in the previous subsection, we can use the mean value theorem to translate the left-hand side into changes in the percentile. That is, there exists a $w^{*}$, such that $w_{p} \leq w^{*} \leq w_{p}^{\prime}$, and

$$
\begin{aligned}
& \int \varphi(s)\left\{F\left(w_{p}^{\prime} \mid s\right)-F\left(w_{p} \mid s\right)\right\} d s+\int \gamma(s)\left\{G\left(w_{p}^{\prime} \mid s\right)-G\left(w_{p} \mid s\right)\right\} d s \\
= & {\left[\int \varphi(s) f\left(w^{*} \mid s\right) d s+\int \gamma(s) g\left(w^{*} \mid s\right) d s\right]\left(w_{p}^{\prime}-w_{p}\right)=q_{p}\left(w_{p}^{\prime}-w_{p}\right) . }
\end{aligned}
$$

This then allows us to express the change in the percentile, $\left(w_{p}^{\prime}-w_{p}\right)$, as

$$
\begin{aligned}
\left(w_{p}^{\prime}-w_{p}\right)= & \frac{1}{q_{p}}\left\{\int \varphi(s)\left\{F\left(w_{p} \mid s\right)-G\left(w_{p} \mid s\right)\right\} d s+\int \gamma(s)\left\{F\left(w_{p}^{\prime} \mid s\right)-G\left(w_{p}^{\prime} \mid s\right)\right\} d s\right\} \\
& -\frac{1}{q_{p}}\left\{\int\left[\left\{F\left(w_{p}^{\prime} \mid s\right)-p\right\}+\left\{G\left(w_{p} \mid s\right)-p\right\}\right]\{\gamma(s)-\varphi(s)\} d s\right\} .
\end{aligned}
$$

Thus, we are able to decompose the change in the percentile in terms of (i) a part that is due to shifts in the distribution functions for each of the subgroups that make up the population and (ii) a part due to the changes in the shares of these subgroups in the population. 
However, these shifts and shares parts do not directly correspond to the composition and wage growth effects that are the focus of our analysis. Extracting these two effects requires an additional reshuffling of the right-hand side terms of (8). In order to disentangle the composition effect from the wage growth effect, we have to divide the population of wage earners into three types of subgroups. The first type consists of those who earn a wage both at the beginning and end of the period. They are subgroups that are part of $S_{S}$. The two subgroups in this set are those who are in the same job and who are NISJ. The second type consists of individuals who are full-time wage and salary workers at the beginning of the year and who flow out of these jobs and become either parttime or self employed, unemployed, or drop out of the labor force. These groups are exiters from full-time employment, denoted by the set $S_{X}$. The final type consists of those who flow into fulltime wage and salary jobs and were either part-time or self employed, unemployed, or not in the labor force at the beginning of the period. These groups of entrants into full-time jobs are part of $S_{N}$. By explicitly defining who enters and exits the group of full-time wage earners we are able to rewrite (8) as

$$
\begin{aligned}
\left(w_{p}^{\prime}-w_{p}\right)=\frac{1}{q_{p}} & \left\{\int_{s \in S_{S}} \varphi(s)\left\{F\left(w_{p} \mid s\right)-G\left(w_{p} \mid s\right)\right\} d s+\int_{s \in S_{S}} \gamma(s)\left\{F\left(w_{p}^{\prime} \mid s\right)-G\left(w_{p}^{\prime} \mid s\right)\right\} d s\right\} \\
& +\frac{1}{q_{p}}\left\{\int_{s \in S_{X}} \varphi(s)\left[\left\{F\left(w_{p}^{\prime} \mid s\right)-p\right\}+\left\{F\left(w_{p} \mid s\right)-p\right\}\right] d s\right\} \\
& -\frac{1}{q_{p}}\left\{\int_{s \in S_{N}} \gamma(s)\left[\left\{G\left(w_{p}^{\prime} \mid s\right)-p\right\}+\left\{G\left(w_{p} \mid s\right)-p\right\}\right] d s\right\} \\
-\frac{1}{q_{p}} & \left\{\int_{s \in S_{S}}\left[\left\{F\left(w_{p}^{\prime} \mid s\right)-p\right\}+\left\{G\left(w_{p} \mid s\right)-p\right\}\right]\{\gamma(s)-\varphi(s)\} d s\right\} .
\end{aligned}
$$

The right-hand side of (9) consists of four terms. The first term captures the effect of the shift in the earnings distribution for those who are full-time employed both at the beginning and at the end of the period on the change in the percentile. The first part of this term quantifies how much the percentile would have changed if the distribution of the population over different groups in $S_{S}$ remained fixed at the one that prevailed at the beginning of the period, i.e. at $\varphi(s)$. The second part captures the same effect, but instead holding the distribution constant at the one observed at the end of the period, $\gamma(s)$. Putting the two parts together, the first term on the right-hand side quantifies how much the percentile changed because of the wage growth of the individuals who were observed working in both periods. This is the wage growth effect. If, for all groups in $S_{s}, F\left(w_{p} \mid s\right)>$ 
$G\left(w_{p} \mid s\right)$ as well as $F\left(w_{p}^{\prime} \mid s\right)>G\left(w_{p}^{\prime} \mid s\right)$, then, just like in Figure 4, there has been a rightward shift in the distribution of weekly earnings of those employed at both the beginning and end of the period and this contributes positively to the change in the percentile of weekly earnings. In that case, the wage growth effect would be positive.

The second term on the right-hand side of (9) measures the effect of flows out of full-time employment on the change in the percentile. Two things contribute to this effect. The first is what fraction of full-time wage and salary workers who flow out of full-time employment, measured by $\varphi(s)$ for $s \in S_{X}$. The second is where in the earnings distribution these exiters were before leaving their jobs. If a disproportionate share of exiters come from below the examined percentile, such that $F\left(w_{p}^{\prime} \mid s\right)>p$ and $F\left(w_{p} \mid s\right)>p$, their exit will cause the percentile to rise. This is the exit component of the composition effect.

The third term on the right-hand side of (9) measures the effect of flows into full-time employment on the change in the percentile. As for the second term, two things contribute to this effect. The first is the fraction of full-time wage and salary workers at the end of the period who are newly employed, measured by $\gamma(s)$ for $s \in S_{N}$. The second is where in the earnings distribution the newly employed locate. Similar to the exit term, if a disproportionate share of newly employed workers locate below the examined percentile, such that $G\left(w_{p}^{\prime} \mid s\right)>p$ and $G\left(w_{p} \mid s\right)>p$, the percentile itself declines. This is the entry component of the composition effect.

As for the last term, if there is more exit than entry, then there is no full replacement of outflows. As a result, the share of those in $S_{s}$ is higher at the end of the period than at the beginning of the period. For example, if those in $S_{s}$ are disproportionately making more than a given percentile, such that $F\left(w_{p}^{\prime} \mid s\right)<p$ and $G\left(w_{p} \mid s\right)<p$ for $s \in S_{S}$, then the shortfall of replacement of outflows leads to an increase in the percentile since the shortfall is effectively replaced by stayers whose earnings are relatively high. This mechanism is captured by the fourth term, which we call the replacement component of the composition effect.

In sum, our decomposition yields exit and entry components for the composition effect for those who move along (i) the part-time and self-employment margin, (ii) the unemployment margin, and (iii) the participation margin. It yields a wage growth effect as well as a replacement component for the composition effect for those (iv) persons who remained in the same job, and (v) persons who changed jobs (NISJ). 
One final detail is worth noting. Since we do not observe the actual distribution and density functions needed to construct the right-hand side of equation (9), we estimate them. The estimation procedure we use is consistent with the one used to construct Median Usual Weekly Earnings, as published by the BLS. The BLS rounds the weekly earnings values reported by individuals to the nearest multiple of $50 .{ }^{20}$ It then linearly interpolates the distribution function over the interval in which the percentile boundary lies, implicitly assuming that the earnings of those who report in the interval that gets rounded to a particular multiple of 50 are uniformly distributed over that interval. To be consistent with this methodology we estimate the distribution and density functions, $F, G, f$, and $g$, in (9) the same way. That is, we group all earnings observations on the nearest multiple of fifty and assume that earnings are uniformly distributed over the intervals that get rounded to each of these points.

This introduces one problem for our percentile decomposition framework. This way of estimating the distribution functions implies that they are not continuously differentiable and, as a result, the mean value theorem that we applied to derive (9) is not applicable. However, we can still use the percentile decomposition. We replace $f\left(w^{*} \mid s\right)$ and $g\left(w^{*} \mid s\right)$ by

$$
f\left(w^{*} \mid s\right)=\frac{F\left(w_{\mathrm{p}}^{\prime} \mid s\right)-F\left(w_{\mathrm{p}} \mid s\right)}{w_{\mathrm{p}}^{\prime}-w_{\mathrm{p}}} \text {, and } g\left(w^{*} \mid s\right)=\frac{G\left(w_{\mathrm{p}}^{\prime} \mid s\right)-G\left(w_{\mathrm{p}} \mid s\right)}{w_{\mathrm{p}}^{\prime}-w_{\mathrm{p}}} \text {. }
$$

In that case (9) still holds and we can thus decompose changes in earnings percentiles. ${ }^{21}$ This method is applicable to any percentile of the earnings distribution. Since we focus in particular on the median in the rest of our analysis, we drop the subscript $p$ when we present the results.

\section{Results}

In the remainder of the paper we present the results of our decomposition of the log changes in the median weekly earnings from the CPS from 1980 through 2011. The results are organized as follows. We begin by reviewing the time series movements of each of the components that go into

\footnotetext{
${ }^{20}$ According to the BLS: “The estimation procedure places each reported or calculated weekly earnings value into $\$ 50$-wide intervals which are centered around multiples of \$50. The actual value is estimated through the linear interpolation of the interval in which the quantile boundary lies." (BLS, 2011)

${ }^{21}$ This estimation method works if $w_{p}^{\prime} \neq w_{p}$. If $w_{p}^{\prime}=w_{p}$ then we use the value of the density implied by the assumption that earnings are uniformly distributed over the intervals that are rounded to the same multiple of 50. The case where $w_{p}^{\prime}=w_{p}=$ $50 i-25$ for $i=1,2,3, \ldots$ and in which this does not work because of the kinked distribution function does not occur in our data.
} 
our analysis. We then describe the key results. First, we consider in detail the composition effect of unemployment, since this is the margin most commonly focused on in macroeconomic models that aim to match the limited variation and cyclicality of aggregate real wages (Gertler and Trigari, 2009, for example). We then show how other groups contribute to the composition effect. Having shown when and by how much the composition effect influences aggregate wages we turn to explaining the wage growth effect, paying particular attention to the role of job switchers. We conclude our results section with an adding up of all the effects and discuss both the average contributions of the composition and wage growth effects and how their respective contributions change over the business cycle.

\section{Share and shift components of the decomposition}

To begin, recall from the derivation above that what matters for our decomposition of the $\log$ change in median earnings are the shares of each subgroup and the (changes) in their earnings distributions. These are the two things displayed in Figures 5 and 6 along with references to the elements of the decomposition in equation (9). Figure 5 shows the time series plots of the shares of the full-time employed made up by each subgroup in the sample, namely same job (SJ), not in the same job (NISJ), part-time/self-employed (PT), unemployed (U), and not in the labor force (NILF).

Panel (a) of the figure shows the share of those classified as "same job" and NISJ as a fraction of the full-time employed. ${ }^{22}$ Taking into account that the data are normalized at the end of the year and that the figure plots the 4-quarter moving average, panel (a) suggests that NISJ transitions are procyclical - they go up when the labor market is strong and then decline during labor market downturns. In Appendix A we describe our imputation results of the composition of NISJ over the business cycle. These results suggest that about two-thirds of those classified as NISJ are job-to-job switchers and that they account for this procyclicality of the NISJ share over the business cycle, shown in panel (a) of Figure 5. This is consistent with the view that when the labor market is strong workers quit more frequently and leave for higher paid jobs (Akerlof, Rose, and Yellen 1988) and when the labor market is weak, layoffs increase and a higher number of persons lose their full-time job, go through unemployment, and end up in a different full-time job a year later. ${ }^{23}$

\footnotetext{
${ }^{22}$ The sudden shift in 1983 is a data anomaly due to the change in occupation codes in the CPS. In particular after 1983 these codes were more detailed, allowing us to be more precise about our "same job" versus "not-in-the-same-job" imputation.

${ }^{23}$ This contrasts somewhat with Hall (2005) who argues that the behavior of quits and layoffs offset such that overall separations are barely cyclical. Our findings suggest that these opposing forces do not cancel out to the same extent for the sample of those
} 
The remaining panels of the figure (panels b-d) plot the time series of entry into and exits out of full-time employment by our three other labor market groups: unemployed, part-time/self employed, and not in the labor force. The first thing to notice is that consistent with Table 2, exiters and enterers account for a small share of the total full-time employed. On average, flows into and out of unemployment are smaller than those along the part-time and self-employment margin as well as the labor force margin. However, as expected, flows into unemployment (exits from fulltime employment into unemployment, panel b) are much more cyclical than those to part-time and self employment or out of the labor force (panels $\mathrm{c}$ and $\mathrm{d}$ ). One notable deviation from this general pattern occurred in 2007, when flows from full-time to part-time employment spiked, leading to about 6 percent of the labor force being part-time employed for economic reasons during 2009 and 2010. The last time that this rate was so high was in October 1982. What seems to be different about the run-up of the rate of part-time employment in the 2007 recession compared to that in 1982 is that it consisted more of persons whose full-time status changed to part-time, rather than the unemployed and labor force entrants being unable to find full-time employment. ${ }^{24}$ Exits from fulltime employment to NILF vary little with the business cycle and are mostly determined by demographic factors and retirement norms. Entry into full-time employment from NILF is, not surprisingly, slightly more procyclical.

In Figure 6 we plot the shifts in the earnings distributions for each of our subgroups. Since we are interested in log changes in median earnings these plots show the shares of our five worker groups moving around the overall median. Specifically, Panel (a) of the figure plots the fraction of full-time employed, classified as either "same job" or NISJ, that moves from below median weekly earnings to above it. In terms of our notation, it is calculated as

$$
\frac{1}{2}\left(F\left(w^{\prime} \mid s\right)-G\left(w^{\prime} \mid s\right)\right)+\frac{1}{2}(F(w \mid s)-G(w \mid s)) \text { for } s \in\{S J, N I S J\}
$$

As can be seen from the panel, during strong labor markets a larger share of job-switchers than jobstayers break through the median. In downturns and recoveries, this pattern is reversed and a larger fraction of those in the same job break through the median. These findings are consistent with the

transitioning from full-time to full-time employment; for these movements the cyclicality of quits seems to dominate. The result is that NISJ transitions in our full-time employed sample are procyclical.

\footnotetext{
${ }^{24}$ This finding is consistent with changes in UI rules in several states that allowed individuals to claim benefits when reducing hours of work as well as when losing jobs.
} 
previous discussion that highlighted the importance of quits in NISJ during expansions versus layoffs in contractions.

Panels (b-d) of Figure 6 show where in the earnings distribution exit and entry for different subgroups occurs. In terms of our notation, these are calculated as

$$
\frac{1}{2}\left(F(w \mid s)+F\left(w^{\prime} \mid s\right)\right) \text { and } \frac{1}{2}\left(G(w \mid s)+G\left(w^{\prime} \mid s\right)\right) \text { for } s \in\{U, P T, N I S J\}
$$

for exiters from and entrants into full employment respectively. The first thing to note from each of these panels is that the vast majority of those who enter full-time employment from any of these states earn less than MWE. This can also be seen in Table 3, rows 3-5. Surprisingly, entry into and exit from unemployment takes place at a higher part of the income distribution than do movements from and to part-time and self-employment and not-in-the-labor-force. This is evident in from the fact that a lower fraction of entries into and exits from full-time employment come from below median earnings for unemployment than for the other two groups.

Turning to the dynamics of the earnings of these flows, panel (b) shows that there is considerable cyclicality in the composition of those exiting (entering) full-time employment into (from) unemployment. During recessions, the fraction of workers moving from full-time employment to unemployment (exits), from below MWE, falls. This is consistent with Mueller (2010) who finds that during recessions the incidence of unemployment among highincome earners increases. This pattern is reversed in expansions, when the share of workers exiting full-time employment to unemployment with earnings below MWE rises. A similar pattern is observed for entries into full-time employment from unemployment but with a lag; the fraction making this transition from below MWE falls during recessions and rises during expansions. This largely reflects that those high-income earners who end up unemployed during a recession generally also find relatively higher paid full-time jobs when they exit unemployment.

Relative to the unemployment subgroup, there is very little cyclicality in the position in the earnings distribution of those who flow into NILF or part-time and self-employment originate. The main pattern in both series is that the gaps between the entries to and exits (from) full-time employment narrow over time, suggesting that in the decomposition most of the cyclical variation in the contributions from the part-time and self-employment and NILF margins will come through their shares rather than shifts in the earnings distributions. 


\section{Decomposition of median weekly earnings growth by subgroup}

To see how the individual patterns displayed in Figures 5 and 6 combine to produce changes in aggregate real earnings growth in the U.S., we turn to our decomposition. Specifically, we use equation (9) to decompose the log-change of median weekly earnings into the wage growth effect and the composition effect. The results are displayed in Figure 7. Panel (a) plots the composition effect which is the replacement components for the "same job" and NISJ subgroups and the net contribution of the entry and exit components for the other subgroups. Panel (b) plots the wage growth effect for those in the same job and NISJ.

Given the number of moving parts underlying the decomposition we begin with a detailed description of how the components displayed in Figures 5 and 6 produce the net composition effect for the unemployment margin shown in panel (a) of Figure 7 and for the NISJ wage growth effect shown in panel (b) of the same figure. These also are the two margins of adjustment commonly thought to explain the bulk of the patterns in aggregate real wage growth.

\section{Composition effect}

In equation (9), up to the scaling factor, $1 / q$, the net composition effect of the unemployment margin is given by

$$
\varphi(U)\left\{\left(F\left(w^{\prime} \mid U\right)-1 / 2\right)+(F(w \mid U)-1 / 2)\right\}-\gamma(U)\left\{\left(G\left(w^{\prime} \mid U\right)-1 / 2\right)+(G(w \mid U)-1 / 2)\right\} .
$$

Here, $\varphi(U)$ is the share of full-time employed at the beginning of the year who are unemployed at the end of the year and $\gamma(U)$ is the share of full-time employed at the end of the year who were unemployed at the start. Both of these shares are plotted in panel (b) of Figure 5. $F\left(w^{\prime} \mid U\right)$ and $F(w \mid U)$ reflect the share of those moving from full-time employment to unemployment who made less than the median wage, measured either at the end and the beginning of the year respectively. $G(. \mid U)$ measures the same share, but for those entering full-time employment from unemployment.

Recall from panel (b) of Figure 6 that unemployed workers pay a displacement penalty such that $G\left(w^{\prime} \mid U\right)>F\left(w^{\prime} \mid U\right)$ and $G(w \mid U)>F(w \mid U)$. In terms of equation (13), this implies that when $\varphi(U) \cong \gamma(U)$ — exit to and entry from unemployment are roughly equal — the composition effect of unemployment pulls down median wage growth since the distribution of earnings for those transitioning from full-time employment to unemployment is higher than for those transitioning from unemployment to full-time employment. Looking at the line for the unemployment margin in 
Figure 7 (panel a), this is exactly what happens on average; the unemployment margin reduces aggregate wage growth. In general then, the composition effect of the unemployed is negative.

Two things cause this, on average, negative effect to fluctuate over the business cycle. The first is when $\varphi(U)$ moves relative to $\gamma(U)$. For example, as can be seen from panel (b) of Figure 5, in economic downturns $\varphi(U)$ goes up and $\gamma(U)$ goes down so that unemployment increases. These cyclical fluctuations make the composition effect of unemployment less negative during recession than during expansions, causing it to move countercyclically.

The second is when the difference between $G(w \mid U)$ and $F(w \mid U)$ rises or falls. This happens when the magnitude of the displacement penalty changes. As can be can be seen from the difference between the dashed and solid lines in panel (b) of Figure 6, in economic downturns the displacement penalty rises as the incidence of unemployment moves up the earnings distribution and reemployed workers take a bigger wage cut. This partially counteracts the countercyclicality of the composition effect of unemployment induced by the movements of $\varphi(U)$ and $\gamma(U)$.

Turning to the other subgroups displayed in panel (a) of Figure 7, all of them contribute to the countercyclicality of the composition effect. Though small, even the replacement components turn out to move countercyclically. In terms of contributions to the composition effect, the part-time and self employment margin contributes more to the composition effect for median weekly earnings growth and cyclicality than the unemployment margin. The magnitude of the part-time and self employment effect relative to other margins owes to the fact that a larger fraction of flows into and out of part-time and self-employment occur below MWE (Figure 6, panel (c)). In contrast to the unemployment margin, the part-time and self-employment effect does not have offsetting components. In business cycle downturns, the share of exits from full-time to part-time rises and there is little change in the earnings difference between entrants to and exits from full-time employment from (to) part-time employment. In line with the shares presented in panel (c) of Figure 5, the importance of the part-time and self-employed for the composition effect increased significantly during the 2007 recession.

\section{Wage growth effect}

The wage growth effects are displayed in Panel (b) of Figure 7; the figure shows the wage growth effect for both the same job and NISJ subgroups. We describe the calculation for the NISJ group, but an analogous strategy applies to the SJ group. 
The wage growth effect for NISJ is obtained by combining the information in panel (a) of Figures 5 and 6 in the context of equation (9), ignoring the scaling coefficient, to obtain

$$
\varphi(N I S J)\{F(w \mid N I S J)-G(w \mid N I S J)\}+\gamma(N I S J)\left\{F\left(w^{\prime} \mid N I S J\right)-G\left(w^{\prime} \mid N I S J\right)\right\}
$$

In particular, the terms in (14) are the share of full-time employed who are NISJ, $1 / 2(\varphi(N I S J)+$ $\gamma(N I S J))$, from Figure 5 and the movements in the earnings distribution of NISJ at the median from Figure $6, \quad 1 / 2\{F(w \mid N I S J)-G(w \mid N I S J)\}+1 / 2\left\{F\left(w^{\prime} \mid N I S J\right)-G\left(w^{\prime} \mid N I S J\right)\right\}$. The net effect of combining these terms is given by the NISJ line in Panel (b) of Figure 7.

The results reveal that those who change jobs over the year contribute more to the wage growth effect than those who remain in the same job. This owes to the fact that the NISJ share of full-time employed is larger while on average the earnings changes of NISJ and same job are similar. When labor markets are tight, the NISJ effect is amplified by an increase in the share and an increase in the fraction moving from below to above the MWE. In labor market downturns the wage growth effect of NISJ and same job groups converge as both the share of NISJ falls and their earnings gains relative to the same job group subside. In general, during labor market expansions the strong performance in terms of wages of those who are in the "same job" and NISJ (displayed in Figure 6) is accentuated by an increase in their share as shown in Figure 5. The result is that the wage growth effect shows large procyclical fluctuations, driven primarily by job-changers, most of whom switch job-to-job.

\section{Putting all the effects together}

Our decomposition allows us to express the time series of 12-month log change of real MWE, $\Delta \ln \left(w_{t}\right)$, as the sum of the seven components shown in Figure 7. We index these components by $c_{i, t}$, where $i=1, \ldots, 7$, such that we can write

$$
\Delta \ln \left(w_{t}\right)=\sum_{i=1}^{7} c_{i, t}
$$

For each of the individual components, $c_{i}$, we discussed the magnitude and cyclicality of their fluctuations. The fact that the individual components add up to the aggregate time series that we study allows us to assess how important they are, on average, over our sample period 1980-2011, for the variance and cyclicality of real MWE growth. 
To measure the contribution of each of the components to the variance of real wage growth, we apply a simple variance decomposition. The additive relationship in equation (15) allows us to write the variance of aggregate real wage growth as the sum of the covariances between each of the individual components, $c_{i, t}$, and the aggregate, $\Delta \ln \left(w_{t}\right)$. Column I of Table 4 lists the share of each of the components in the variance of real wage growth. Rows 2 through 6 of the table show that each of the composition effects only account for a small share of the variance of real wage fluctuations. In total, the composition effect accounts for 8.8 percent of the variance of real MWE growth (row 7, column I). The other 91.2 percent is due to the wage growth effect. In fact, wage changes of those who are NISJ alone account for more than half of the fluctuations in real wage growth over the past three decades (row 9, column I).

As for the cyclicality of real wage growth, we measure it by the coefficient, $\beta$, from a regression of real wage growth on the level of the unemployment rate, $u_{t}$. Both real wage growth as well as the unemployment rate are measured in percentage points in this regression. The particular regression equation is

$$
\Delta \ln \left(w_{t}\right)=\alpha+\beta u_{t}+\varepsilon_{t} .
$$

The coefficient $\beta$ is reported in row 1 of column II of Table 3 and equals -0.112 and is not significant. This indicates that over the past 30 years real wage growth has only been mildly procyclical. Real wage growth has tended to be high when the unemployment rate was low and vice versa. However, this relationship has not been particularly strong, leading to the statistical insignificance of the coefficient.

By construction, the cyclicality coefficient, $\beta$, is the sum of seven component-specific cyclicality coefficients, $\beta_{i}$ for $i=1, \ldots, 7$, obtained using regressions of the form

$$
c_{i, t}=\alpha_{i}+\beta_{i} u_{t}+\varepsilon_{i, t}
$$

These component-specific coefficients are listed in rows 2 through 10 of column II of Table 4. As can be seen from the table, on the one hand, each of the composition effects, except that for unemployment, is significantly countercyclical. On the other, each of the wage growth effects is significantly procyclical. Though the wage growth effect is more important than the composition effect for the cyclicality of real wage growth, half of its movements over the business cycle are undone by the composition of entries into and exits out of full-time employment. This is what 
makes the aggregate cyclicality coefficient negative, just like that associated with the wage growth effect, but statistically insignifant.

Table 4 quantifies the average importance of the composition and wage growth effects for the variance and cyclicality of real MWE growth over the past 30 years. It hides, however, that the relative importance of these effects varies over the business cycle and differs across recessions and expansions. This variation can be seen in Figure 8 which plots the time series of the contributions of the wage growth and composition effects to real wage growth.

The first thing that stands out from the figure is that the wage growth effect was especially important during the strong labor markets of the mid 1980's and the second half of the 1990's. It's impact on real wages was much more subdued during the 2000's. Moreover, the second thing that Figure 8 reveals is that during the first three of the four recessions in our sample, the offsetting countercyclicality of the composition effect was not particularly large. However, during the 2007 recession the composition effect turned from negative to positive, something previously unseen in the data. This large increase in the composition effect means that real wage growth in 2008 and 2009 was greatly affected by changes in the composition of the workforce. In terms of the importance of the composition effect for growth in median usual weekly earnings the 2007 recession is an outlier compared to the three recessions before.

\section{Conclusion}

Using data from the Current Population Survey from 1980 through 2011 we examined what drives the variation and cyclicality in the growth rate of real wages over time. To do this we employed a novel decomposition technique that allows us to divide changes in percentiles of aggregate usual weekly earnings growth into the part associated with the wage growth of persons employed at the beginning and end of the period (the wage growth effect) and the part associated with changes in the composition of earners (the composition effect).

Our results show that the relative importance of these two effects varies widely over the business cycle. When the labor market is tight, job-changers get high wage changes, making them account for about half of the variation in median weekly earnings growth over our sample. Their wage growth as well as that of job stayers is procylical. During labor market downturns this 
procylicality is partly offset by the change in the composition of the workforce. As a result, aggregate wages exhibit only limited cyclicality. Surprisingly, the composition effect works primarily through the part-time employment margin. Remarkably, the unemployment margin neither accounts for much of the variation nor much of the cyclicality of median weekly earnings.

Our conclusion that job switchers are more important for understanding real wage growth than flows in and out of unemployment has an important implication for studies that try to reconcile real wage cyclicality in macroeconomic models with search frictions. Such studies often, for simplicity, assume that the separation rate from employment is exogenously given. However, our results suggest that such an assumption would mean discarding the cyclical fluctuations in the composition of these separations that drive the bulk of U.S. wage growth. ${ }^{25}$ This suggests that, in order to understand the magnitude of variations in real wage growth, one has to explain the reasons why people switch jobs, especially job-to-job switches, and how this affects their wages.

\section{References}

Abraham, Katharine G., and John C. Haltiwanger (1995), "Real Wages and the Business Cycle," Journal of Economic Literature, 33, 1215-1264.

Akerlof, George A., Andrew K. Rose, and Janet L. Yellen (1988), "Job Switching and Job Satisfaction in the U.S. Labor Market," Brookings Papers on Economic Activity, 1988(2): 495582.

Altonji, Joseph G. and Paul J. Devereux, (2000) "The Extent and Consequences of Downward Nominal Wage Rigidity,” Research in Labor Economics, 19, 383-431.

Barattieri, Alessandro, Susanto Basu, and Peter Gottschalk (2010), "Some Evidence on the Importance of Sticky Wages," Boston College Working Paper \#740.

Barro, Robert J. and Robert G. King (1984). "Time-separable Preferences and IntertemporalSubstitution Models of Business Cycles," The Quarterly Journal of Economics, 99, 817-39.

Bartelsman, Eric J., and Ricardo J. Caballero, and Richard K. Lyons (1994). "Customer- and Supplier-Driven Externalities," American Economic Review, 84, 1075-84.

Bartelsman, Eric J., John Haltiwanger and Stefano Scarpetta, (2004). "Microeconomic Evidence of Creative Destruction in Industrial and Developing Countries," Tinbergen Institute Discussion Papers, 04-114/3, Tinbergen Institute.

\footnotetext{
${ }^{25}$ Hagedorn and Manovskii (2010) drop this assumption and show how job-to-job transitions in their model of frictional unemployment are important to match the observed cyclicality of real wages.
} 
Bils, Mark. J. (1985) "Real Wages over the Business Cycle: Evidence from Panel Data," Journal of Political Economy, 93(4), 666-689.

Bowlus, Audra, Haoming Liu, and Chris Robinson (2002), "Business Cycle Models, Aggregation, and Real Wage Cyclicality," Journal of Labor Economics, 20, 308-335.

Bureau of Labor Statistics (BLS) (2011), "Usual Weekly Earnings Technical Note," URL: http://www.bls.gov/news.release/wkyeng.tn.htm [last accessed: 02/23/11]

Card, David, and Dean Hyslop (1997). "Does Inflation 'Grease the Wheels of the Labor Market'?" in Reducing Inflation: Motivation and Strategy Christina D. Romer and David H. Romer (eds.), Chicago: University of Chicago Press.

Christiano, Lawrence J. and Martin Eichenbaum (1992), "Current real-business cycle theories and aggregate labor-market fluctuations," American Economic Review. 82, 430-450.

Devereux, Paul J. (2001), "The Cyclicality of Real Wages Within Employer-Employee Matches," Industrial and Labor Relations Review , 54 (4), 835-850.

Dickens, William T., Lorenz Goette, Erica L. Groshen, Steinar Holden, Julian Messina, Mark E. Schweitzer, Jarkko Turunen, Melanie E. Ward (2007), "How Wages Change: Micro Evidence from the International Wage Flexibility Project," Journal of Economic Perspectives, 21, 195214.

DiNardo, John, Nicole M. Fortin, and Thomas Lemieux (1996), "Labor Market Institutions and the Distribution of Wages, 1973-1992: A Semiparametric Approach," Econometrica, 64 (5), 10011044.

Elsby, Michael, Bart Hobijn, and Ayșegül Șahin (2010) "The Labor Market in the Great Recession," Brookings Papers on Economic Activity, Spring 2010, 1-48.

Fallick, Bruce, and Charles Fleischman (2004), "Employer-to-Employer Flows in the U.S. Labor Market: The Complete Picture of Gross Worker Flows," Finance and Economics Discussion Series 2004-34, Board of Governors of the Federal Reserve System.

Farber, Henry S. (1997), "The Changing Face of Job Loss in the United States, 1981-1995," Brookings Papers on Economic Activity (Microeconomics), pp. 55-128.

Farber, Henry S. (2005), "What Do We Know About Job Loss in the United States? Evidence From the Displaced Worker Surveys 1984-2004," Federal Reserve Bank of Chicago Economic Perspectives, 29 (2), pp. 13-28.

Fortin, Nicole M., Thomas Lemieux, and Sergio Firpo (2011), "Decomposition Methods in Economics," Handbook of Labor Economics, Volume 4A, 1-102. Amsterdam: North Holland.

Fujita, Shigeru and Garey Ramey (2009), "The Cyclicality of Job Loss and Hiring," International Economic Review, 50, 415-430.

Galí, Jordi (2011), "The Return of the Wage Phillips Curve," Journal of the European Economic Association, 9, 436-461.

Gertler, Mark L., and Antonella Trigari (2009), "Unemployment Fluctuations with Staggered Nash Wage Bargaining," Journal of Political Economy, 117, 38-86. 
Hagedorn, Marcus, and Iourii Manovskii (2010), "Job Selection and Wages over the Business Cycle," mimeo, University of Pennsylvania.

Hall, Robert E. (2005), "Job Loss, Job Finding, and Unemployment in the U.S. Economy over the Past Fifty Years,” NBER Macroeconomics Annual, 2005, 101-137.

Hansen, Gary D. (1985), "Indivisible Labor and the Business Cycle," Journal of Monetary Economics, 16, 309-327.

Hines, James R., Hillary Hoynes, and Alan B. Krueger (2001), “Another Look at Whether A Rising Tide Lifts All Boats,” NBER Working Paper \#8412.

Juhn, Chinhui, and Simon Potter (2006), "Changes in Labor Force Participation in the United States," Journal of Economic Perspectives, vol. 20, 27-46.

Kim, Seik (2009), "Sample Attrition in the Presence of Population Attrition," UWEC-2009-02 Working Paper.-

Kudlyak, Marianna (2010), “Are Wages Rigid Over the Business Cycle?” Economic Quarterly, 96, 179-199.

Kydland, Finn E. and Edward C. Prescott, (1982). "Time to Build and Aggregate Fluctuations," Econometrica, 50, 1345-70.

Lebow, David E., Raven E. Saks, and Beth Anne Wilson (2003), "Downward Nominal Wage Rigidity: Evidence from the Employment Cost Index," Advances in Macroeconomics, 3 article 2, 1-28.

Lucas, Robert E.B. (1977), "Hedonic Wage Equations and Psychic Wages in the Returns to Schooling," American Economic Review. 64 (4), 549-558

Madrian, Brigitte. C., and Lars John Lefgren (1999), “A Note on Longitudinally Matching Current Population Survey (CPS) Respondents,” NBER Working Paper Series \#t0247.

Mankiw, N. Gregory, (1989), "Real Business Cycles: A New Keynesian Perspective,” Journal of Economic Perspectives, 3 (3), 79-90.

Martins, Pedro, Gary Solon, and Jonathan Thomas (2010), "Measuring What Employers Really Do about Entry Wages over the Business Cycle,” NBER Working Paper Series \#15757.

Moscarini, G., \& Thomsson, K. (2008). Occupational and Job Mobility in the US. Scandinavian Journal of Economics , 109 (4), 807-836.

Mueller, Andreas (2010), "Separations, Sorting and Cyclical Unemployment," mimeo, IIES Stockholm University.

Nagypál, Éva (2008), “Worker reallocation over the business cycle: The importance of job-to-job transitions," mimeo, Northwestern University.

Nekarda, Christopher J. (2009), "A Longitudinal Analysis of the Current Population Survey: Assessing the Cyclical Bias of Geographic Mobility," mimeo, Federal Reserve Board of Governors.

Perry, George L. (1972), "Real Spendable Weekly Earnings," Brookings Papers on Economic Activity, No. 3, 779-787. 
Daly, Hobijn, and Wiles

Pissarides, Christopher A. (2009), "The Unemployment Volatility Puzzle: Is Wage Stickiness the Answer?" Econometrica, 77, 1339-1369.

Rotemberg, Julio J and Woodford, Michael, (1992). "Oligopolistic Pricing and the Effects of Aggregate Demand on Economic Activity," Journal of Political Economy, University of Chicago Press, 100 (6), 1153-1207.

Shimer, Robert (2005), "The Cyclical Behavior of Equilibrium Unemployment and Vacancies," American Economic Review, 95, 25-49.

Shimer, Robert (2007), "Reassessing the Ins and Outs of Unemployment," NBER Working Paper \#13421.

Solon, Gary, Robert Barsky, and Jonathan A. Parker (1994), "Measuring the Cyclicality of Real Wages: How Important is Composition Bias," Quarterly Journal of Economics , 109 (1), 1-25.

Swanson, Eric T. (2007), "Real Wage Cyclicality in the Panel Study of Income Dynamics," Scottish Journal of Political Economy, 54, 617-647. 
Dissecting Aggregate Real Wage Fluctuations

\section{A. Data and Variable Details}

\section{Matching individuals across CPS interviews in different months}

We use the matching criteria employed by Madrian and Lefgren (1999) for matching the outgoing rotations and Moscarini and Thomsson (2008) for matching month-to-month transitions. Our matching procedures are similar to Fallick and Fleischman (2004) and Card and Hyslop (1997). ${ }^{26}$ Specifically, individuals in our sample must match on age $(+3$ or -1 between subsequent interviews), race, household ID, and line number. ${ }^{27}$ Our procedure produces match rates that are identical are quite similar to previous researchers.

One thing to note is that our match procedure could introduce some bias into our results due to geographic mobility. Our results are conditional on staying within the same household, and people within the unemployment, NILF, and NISJ margin are more likely to move. However, Nekarda (2009) shows that the effect of geographic mobility on aggregate CPS measures such as the job finding rate and the separation rate is small. Nekarda (2009) also incorporates a match similar to ours, which allows for households to non-report or misreport in months between valid matches.

\section{Constructing the same-job variable}

Various researchers have used strategies to identify when individuals switch jobs in the CPS. Card and Hyslop (1997) compare 2-digit industry and occupation codes between IM4 and IM8 ${ }^{28}$. In 1994, new variables were introduced to the CPS to help identify month-to-month changes in employment. Fallick and Fleishmann (2004) and Nagypál (2008) use one of these variableswhether an individual still works for the same employer as last month, providing the employer's name. Both of these studies look at month-to-month transitions. This is also touched on in Moscarini and Thomsson (2008)'s study of occupational mobility. Our "Same Job" definition can

\footnotetext{
${ }^{26}$ Fallick and Fleischman (2004) require age to be decreased by no more than one year or increased by no more than two years. Card and Hyslop (1997) use age plus or minus one year.

${ }^{27}$ Within 1994 and 1995, HHID's are only consistent within state, so we add a state constraint within those years. For 2003-2004 we don't use the HRSAMPLE and HRSERSUF variables, since they seem to be randomized, and HHID coupled with the demographic variables successfully matches individuals.

${ }^{28}$ From their appendix: "The industry and occupation are matched using detailed (2-digit) industry and occupation codes for all years except 1982-83, 1983-84, and 1988-89. Matching for the 1983-84 sample is based on 3-digit 1980 census codes; for the $1982-83$ sample, industry is matched using the detailed (2-digit) codes which are comparable across years, while occupation was matched using an algorithm devised to convert 1970 census 3-digit5 occupation codes to their 1980 census counterparts; and for the 198889 sample, occupation was matched using the detailed codes, and an algorithm was devised to match the detailed industry codes."
} 
be considered a combination of the month-month SJ calculation of Fallick and Fleischman (2004), Nagypál (2008) and the year-to-year SJ calculation of Card and Hyslop (1997). We want to use all available information on a matched individual, but we are also constrained by missing data between IM4 and IM5.

Our procedure then is as follows. After 1994, we define a job stayer as an individual observed as employed in IMs 4, 5, 6, 7, and 8, with the same detailed industry and occupation in each of these months, and who reports being with the same employer and reports the same job description and job duties, or who has missing values for these dependent-coding variables in MIS 6, 7, and 8. Nagypál (2008) and Fallick and Fleischman (2004) only use the "same employer" variable, so including these three variables enables a wider definition of job re-negotiation. Prior to 1994, we do not have the dependent coding variables, and industry and occupation data is reported anew each month. Thus, to get a "same job" measure, we match industry and occupation between IMs 4 and 8, and at least 2 out of the 3 months in IMs 5, 6, and 7, keeping the constraint of employment throughout IMs 4-8. This gives us a reasonably consistent same job rate across the 1994 boundary, and a slightly more restrictive test than Card and Hyslop (1997), who only constrained industry, occupation, and labor status in IM 4 and IM 8. Our "Same Job" rates are consistent with other estimates in the literature.

\section{Not-in-the-same-job (NISJ) versus job-to-job (J2J) transitions}

Following Fallick and Fleischman (2004) and Nagypál (2008) we consider a job-to-job transition as one in which a CPS respondent reports to be employed in a particular job in one month and another job in the next month. Unfortunately, this definition does not account for the possibility of such a worker having moved through a short spell of unemployment or part-time or self employment during the month in between the two responses. Since identifying the fraction of the NISJ individuals who moved directly from one full-time job to another, i.e. job-to-job $(J 2 J)$ transitions is important for our study, we impute the fraction of NISJ transitions that are $J 2 J$.

Our imputation method relies heavily on the gross worker flows measurement methodologies used in Shimer (2005) and Fujita and Ramey (2009). Given the CPS survey structure (see Table 1) individuals we classify as NISJ consist of four groups: (i) Those who have missing data for IM5, IM6, or IM7 (ii) employed in IM4 and employed in another job in MIS8 but either unemployed, not in the labor force, or part-time or self employed in IM5, IM6, or IM7, (ii) not in (i) and (ii) and 
employed in IM4 in the same job in IM5 and in a different job at IM8, (iii) not in (i) and (ii) and employed in IM4 and in a different job in IM5.

Those in (ii) are not part of $J 2 J$ transitions. These are individuals who have not been employed for the whole 12-month period between the two levels of earnings they report. For our imputation, we ignore temporary layoffs and assume that everyone who reports to have the same job as 8 months earlier has remained in that job over the intervening period. Hence, we classify those in (iii) as part of $J 2 J$ transitions.

The imputation is made complicated by those in (iv) and (i). We discuss the imputation for those in (iv) first. Some of the individuals in that group who changed jobs between IM4 and IM5 actually went through unemployment, dropped out of the labor force, or were part-time of self employed. However, these episodes are not observed because they occurred during the eight months when the individuals were not part of the CPS sample. Hence, we have to impute what share of those in group (iii) did not experience any episodes of unemployment, part-time employment, or self employment and did not drop out of the labor force.

We impute this share by assuming that labor market status transitions follow a first-order Markov process. ${ }^{29}$ We denote the different labor market statuses as: (i) $E$ full-time employed in the same job as at the beginning of the period, ( $i i) E^{\prime}$ full-time employed in a different job as at the end of the period, (iii) $U$ unemployed, (iv) $N$ not in the labor force, and (v) PT part-time or self employed. The arrow $\stackrel{4,5}{\rightarrow}$ denotes the transition during the 9 months between IM4 and IM5.

The first-order Markov assumption allows us to write transition probabilities over multiple months in terms of monthly transition probabilities. We define these monthly transition probabilities in month $t$ as

$$
m_{l, k}(t), \text { where } l, k \in\left\{E, E^{\prime}, U, N, P T\right\} .
$$

Here $m_{l, k}(t)$ is the fraction of persons with labor market status $l$ at the beginning of the period that end up in $k$ at the end of the period.

As we discussed above, we assume that persons who are in the same job in IM5 as in IM4 have been continuously employed in that job. This implies that

\footnotetext{
${ }^{29}$ This assumption means that, due to data-limitations, we do not account for duration dependence of unemployment outflow rates, or tenure duration dependence of worker separation rates. Consequently, our imputations should only be interpreted as indicative of cyclical fluctuations of the composition of the NISJ group in our sample rather than a precise estimate.
} 


$$
m_{l, E}(t)=0, \text { for } l \in\left\{E^{\prime}, U, N, P T\right\} .
$$

Note that $m_{E, E}(t)$ is the probability of remaining full-time employed in the same job during the month and $m_{E, E^{\prime}}(t)$ is the probability of a job-to-job transition. ${ }^{30}$

We construct the Markov transition matrix that is associated with these probabilities based on monthly matched CPS data, similar to Shimer (2007), Fujita and Ramey (2009), and Elsby, Hobijn, and Şahin (2010).

The share we are imputing is the ratio of two probabilities. The numerator is the probability that an individual reports to have changed jobs in IM5 relative to nine months before in IM4 and has not flown through $U, N$, or $P T$. This probability can be written as

$$
\operatorname{Pr}\left[E \stackrel{4,5}{\rightarrow} E^{\prime} \cap \text { not through } U, N, \text { or } P T\right]=\prod_{t=2}^{10}\left\{m_{E, E}(t)+m_{E, E^{\prime}}(t)\right\}-\prod_{t=2}^{10} m_{E, E}(t) .
$$

The denominator is much harder to impute. It is the probability that an individual reports to have changed jobs in IM5 relative to eight nine months before in IM4 irrespective of what she or he did in the meanwhile. It is

$$
\operatorname{Pr}\left[E \stackrel{4,5}{\rightarrow} E^{\prime}\right]=\left[\begin{array}{lllll}
0 & 1 & 0 & 0 & 0
\end{array}\right]\left(\prod_{t=2}^{10} \boldsymbol{M}(t)\right)\left[\begin{array}{lllll}
1 & 0 & 0 & 0 & 0
\end{array}\right]^{\prime}
$$

Here, the Markov transition matrix $\boldsymbol{M}(t)$ is given by

$$
\boldsymbol{M}(t)=\left[\begin{array}{ccccc}
m_{E, E}(t) & 0 & 0 & 0 & 0 \\
m_{E, E^{\prime}}(t) & \left(m_{E, E}(t)+m_{E, E^{\prime}}(t)\right) & m_{P T, E}(t) & m_{U, E}(t) & m_{N, E}(t) \\
m_{E, P T}(t) & m_{E, P T}(t) & m_{P T, P T}(t) & m_{U, P T}(t) & m_{N, P T}(t) \\
m_{E, U}(t) & m_{E, U}(t) & m_{P T, U}(t) & m_{U, U}(t) & m_{N, U}(t) \\
m_{E, N}(t) & m_{E, N}(t) & m_{P T, N}(t) & m_{U, N}(t) & m_{N, N}(t)
\end{array}\right] .
$$

Thus, only a fraction

$$
\operatorname{Pr}\left[E \stackrel{4,5}{\rightarrow} E^{\prime} \cap \text { not through } U, N, \text { or } P T\right] / \operatorname{Pr}\left[E \stackrel{4,5}{\rightarrow} E^{\prime}\right]
$$

of those in the third group of individuals classified as NISJ will be imputed as having gone directly from job to job rather than flowing through unemployment, part-time or self employment, or temporarily leaving the labor force.

\footnotetext{
${ }^{30}$ This job-to-job transition is slightly different from that reported in Fallick and Fleischman (2004) and Nagypál (2008) because it is conditional on full-time employment.
} 
As for those in group (i) we can do the same as for those in (iv). The share of this group that we attribute to NISJ is given by

$$
\operatorname{Pr}\left[E \stackrel{4,8}{\rightarrow} E^{\prime} \cap \text { not through } U, N, \text { or } P T\right] / \operatorname{Pr}\left[E \stackrel{4,8}{\rightarrow} E^{\prime}\right]
$$

The numerator and denominator for this group are calculated in a very similar way as for group (iv). In particular

$$
\operatorname{Pr}\left[E \stackrel{4,8}{\rightarrow} E^{\prime} \cap \text { not through } U, N, \text { or } P T\right]=\prod_{t=2}^{13}\left\{m_{E, E}(t)+m_{E, E^{\prime}}(t)\right\}-\prod_{t=2}^{13} m_{E, E}(t),
$$

and

$$
\operatorname{Pr}\left[E \stackrel{4,8}{\rightarrow} E^{\prime}\right]=\left[\begin{array}{lllll}
0 & 1 & 0 & 0 & 0
\end{array}\right]\left(\prod_{t=2}^{13} \boldsymbol{M}(t)\right)\left[\begin{array}{lllll}
1 & 0 & 0 & 0 & 0
\end{array}\right]^{\prime}
$$

That is, if one or more observations in IM5, IM6, and IM7 are missing for an individual we treat all these observations as missing and impute the share of such individuals that are $J 2 J$ through the assumed first-order Markov transition process.

The first-order Markov assumption in our imputation method assumes that a person flowing through unemployment is just as likely to become unemployed later in the year as someone that did not. In actuality, this person is more likely to become unemployed (again) but the CPS data do not allow us to correct for this. Not correcting for this leads to an overestimate of the number of persons flowing through unemployment (and non-participation and part-time and self-employment for the same reason). Hence, it is best to interpret our imputed fraction of NISJ flows that are $\mathbf{J} 2 \mathbf{J}$ as a lowerbound estimate.

Figure A.1 shows the results of our imputation. The figure indicates that, on average, a bit less than two-thirds of NISJ flows are J2J. Just like quits as a share of separations in the Job Openings and Labor Turnover Survey, J2J flows are procyclical, increasing during the strong labor market at the end of the 1990's, with a bit of a lull during the dip in 1998, and again increasing from 2006 through 2007. Their share sharply dropped during the 2007 recession. ${ }^{31}$ This is consistent with Akerlof, Rose, and Yellen (1988) who argue that job-to-job quits in pursuit of higher wages and job satisfaction drive a large part of U.S. labor market dynamics.

\footnotetext{
${ }^{31}$ It is important to note that, because we count changes of the job description of a worker who stays with the same employer as a change in jobs, we find more job-to-job switches than studies, like Fallick and Fleishmann (2004) and Nagypál (2008), which consider job-to-job switches conditional on changing employers. Moreover, we only consider switches from one full-time job to another.
} 
Daly, Hobijn, and Wiles

\section{B. Mathematical details}

\section{Derivation of equation (2)}

Equation (2) can be derived by realizing that

$$
\begin{aligned}
0 & =F\left(w_{p}\right)-G\left(w_{p}^{\prime}\right) \\
& =\left(F\left(w_{p}\right)-F\left(w_{p}^{\prime}\right)\right)+\left(F\left(w_{p}^{\prime}\right)-G\left(w_{p}^{\prime}\right)\right)=\left(F\left(w_{p}\right)-G\left(w_{p}\right)\right)+\left(G\left(w_{p}\right)-G\left(w_{p}^{\prime}\right)\right) \\
& =\left(F\left(w_{p}\right)-F\left(w_{p}^{\prime}\right)\right)+\left(G\left(w_{p}\right)-G\left(w_{p}^{\prime}\right)\right)+\left(F\left(w_{p}\right)-G\left(w_{p}\right)\right)+\left(F\left(w_{p}^{\prime}\right)-G\left(w_{p}^{\prime}\right)\right) .
\end{aligned}
$$

Moving the first two terms in this expression from the right-hand side to the left-hand side yields equation (2).

\section{Derivation of equation (6)}

The version of (2) for more than one subgroup, $s$, reads

$$
\begin{aligned}
& \int \varphi(s)\left[F\left(w_{p}^{\prime} \mid s\right)-F\left(w_{p} \mid s\right)\right] d s+\int \gamma(s)\left[G\left(w_{p}^{\prime} \mid s\right)-G\left(w_{p} \mid s\right)\right] d s \\
= & \int \varphi(s) F\left(w_{p} \mid s\right) d s-\int \gamma(s) G\left(w_{p} \mid s\right) d s+\int \varphi(s) F\left(w_{p}^{\prime} \mid s\right) d s-\int \gamma(s) G\left(w_{p}^{\prime} \mid s\right) d s .
\end{aligned}
$$

The right-hand side of this expression can be rewritten as

$$
\begin{gathered}
\int \varphi(s) F\left(w_{p} \mid s\right) d s-\int \gamma(s) G\left(w_{p} \mid s\right) d s+\int \varphi(s) F\left(w_{p}^{\prime} \mid s\right) d s-\int \gamma(s) G\left(w_{p}^{\prime} \mid s\right) d s \\
=\int \varphi(s)\left[F\left(w_{p} \mid s\right)-G\left(w_{p} \mid s\right)\right] d s-\int(\gamma(s)-\varphi(s)) G\left(w_{p} \mid s\right) d s+ \\
\quad \int \gamma(s)\left[F\left(w_{p}^{\prime} \mid s\right)-G\left(w_{p}^{\prime} \mid s\right)\right] d s-\int(\gamma(s)-\varphi(s)) F\left(w_{p}^{\prime} \mid s\right) d s .
\end{gathered}
$$

Combining terms, we obtain equation (6).

\section{Derivation of equation (9)}

Equation (9) follows from 


$$
\begin{aligned}
\left(w_{p}^{\prime}-w_{p}\right)= & \frac{1}{q_{p}}\left\{\int_{s \in S_{S}} \varphi(s)\left\{F\left(w_{p} \mid s\right)-G\left(w_{p} \mid s\right)\right\} d s+\int_{s \in S_{S}} \gamma(s)\left\{F\left(w_{p}^{\prime} \mid s\right)-G\left(w_{p}^{\prime} \mid s\right)\right\} d s\right\} \\
& -\frac{1}{q_{p}}\left\{\int_{s \in S_{S}}\left[\left\{F\left(w_{p}^{\prime} \mid s\right)-p\right\}+\left\{G\left(w_{p} \mid s\right)-p\right\}\right]\{\gamma(s)-\varphi(s)\} d s\right\} \\
& +\frac{1}{q_{p}}\left\{\int_{s \in S_{X}} \varphi(s)\left\{F\left(w_{p} \mid s\right)-G\left(w_{p} \mid s\right)\right\} d s\right\} \\
& -\frac{1}{q_{p}}\left\{\int_{s \in S_{X}}\left[\left\{F\left(w_{p}^{\prime} \mid s\right)-p\right\}+\left\{G\left(w_{p} \mid s\right)-p\right\}\right]\{\gamma(s)-\varphi(s)\} d s\right\} \\
& +\frac{1}{q_{p}}\left\{\int_{s \in S_{N}} \gamma(s)\left\{F\left(w_{p}^{\prime} \mid s\right)-G\left(w_{p}^{\prime} \mid s\right)\right\} d s\right\} \\
& -\frac{1}{q_{p}}\left\{\int_{s \in S_{N}}\left[\left\{F\left(w_{p}^{\prime} \mid s\right)-p\right\}+\left\{G\left(w_{p} \mid s\right)-p\right\}\right]\{\gamma(s)-\varphi(s)\} d s\right\} \\
= & \left.\frac{1}{q_{p}}\left\{\int_{s \in S_{S}} \varphi(s)\left\{F\left(w_{p} \mid s\right)-G\left(w_{p} \mid s\right)\right\} d s+\int\right\}_{s \in S_{S}} \gamma(s)\left\{F\left(w_{p}^{\prime} \mid s\right)-G\left(w_{p}^{\prime} \mid s\right)\right\} d s\right\} \\
& +\frac{1}{q_{p}}\left\{\int_{s \in S_{X}} \varphi(s)\left\{F\left(w_{p} \mid s\right)+F\left(w_{p}^{\prime} \mid s\right)-2 p\right\} d s\right\} \\
& -\frac{1}{q_{p}}\left\{\int_{s \in N} \gamma(s)\left\{G\left(w_{p} \mid s\right)+G\left(w_{p}^{\prime} \mid s\right)-2 p\right\} d s\right\} \\
& -\frac{1}{q_{p}}\left\{\int_{s \in S_{S}}\left[\left\{F\left(w_{p}^{\prime} \mid s\right)-p\right\}+\left\{G\left(w_{p} \mid s\right)-p\right\}\right]\{\gamma(s)-\varphi(s)\} d s\right\} . \\
&
\end{aligned}
$$

This is the equation we are supposed to derive.

\section{Comparison of our percentile decomposition with DiNardo, Fortin, and Lemieux (1996)}

The percentile decomposition that we introduced in this paper is not the first one that can be used. Our decomposition is almost directly derived from a standard shift-share decomposition in means but then translated into shifts in earnings distribution functions and changes in the composition, shares, of the full-time employed.

An alternative is the decomposition by DiNardo, Fortin, and Lemieux (DFL, 1996). DFL do not specifically explain how their methodology can be used to decompose changes in percentiles. This is actually explained is a more general framework in Fortin, Lemieux, and Firpo (2011).

Where our decomposition measures changes in the distribution function evaluated at the percentile at the beginning and at the end of the period, i.e. lines $A$ and $B$ in figure 4 , and then uses 
the mean value theorem to translate changes in the distribution function into changes in the percentile, the DLF decomposition involves the calculation of counterfactual percentiles.

This difference between these two methods is illustrated in figure A.2. The top panel, (a), of the figure illustrates our percentile decomposition in an extended version of figure 4 . In addition to the distribution functions at the beginning at the end of the period, Panel $(a)$ of figure A.2 also contains two counterfactual distribution functions. The first, $\gamma(s) F(W \mid s)$, is the one that would have prevailed if all subgroups had their own conditional earnings distribution from the beginning of the period and the only thing that happened was a shift in the composition of the full-time employed from $\varphi(s)$ to $\gamma(s)$. The second, $\varphi(s) G(W \mid s)$, is the one that would have prevailed if all subgroups had their own conditional earnings distribution from the end of the period and the only thing that happened was a shift in the composition of the full-time employed from $\gamma(s)$ to $\varphi(s)$. Our decomposition evaluates what is the fraction of earners whose earnings crossed the percentile evaluated either at the beginning of the period, $w_{p}$, or at the end of the period, $w^{\prime}{ }_{p}$.

In terms of figure 4 , the former fraction is given by A. Figure A.2 shows that this fraction can be decomposed as

$$
\begin{aligned}
A & =A_{\text {share }}+A_{\text {shift }}=F\left(w_{p}\right)-G\left(w_{p}\right) \\
& =\left\{F\left(w_{p}\right)-\int_{s} \gamma(s) F\left(w_{p} \mid s\right) d s\right\}+\left\{\int_{s} \gamma(s) F\left(w_{p} \mid s\right) d s-G\left(w_{p}\right)\right\} \\
& =\int(\varphi(s)-\gamma(s)) F\left(w_{p} \mid s\right) d s-\int \gamma(s)\left(F\left(w_{p} \mid s\right)-G\left(w_{p} \mid s\right)\right) d s .
\end{aligned}
$$

Thus, $A_{\text {share }}$ is the change in the value of the earnings distribution function at the percentile at the beginning of the period that is attributable to the change in the shares of the subgroups that make up full-time wage and salary earners. While, $A_{\text {shift }}$ is the change in the earnings distribution function due to the earnings distribution functions of each of the underlying subgroups changing.

Similarly, the fraction of earners whose earnings crossed the percentile at the end of the period, given by $B$, can also be decomposed into shift and a share part.

Our decomposition then aggregates the shift and share parts of $A$ and $B$ uses the mean value theorem to translate those into relative contributions to the changes in the percentile. We then reshuffle the shift and share terms to obtain a decomposition in parts that are better interpreted as the composition and the wage growth effects. 
The DFL decomposition requires the construction of counterfactual percentiles. Define these counterfactual percentiles, $\widetilde{w}_{p}$ and $\widetilde{w}_{p}^{\prime}$ as

$$
p=F\left(w_{p}\right)=G\left(w_{p}\right)=\int_{s} \gamma(s) F\left(\widetilde{w}_{p} \mid s\right) d s=\int_{s} \varphi(s) G\left(\widetilde{w}_{p}^{\prime} \mid s\right) d s
$$

Thus, $\widetilde{w}_{p}$ would have been the $p$-th earnings percentile if the each of the subgroups had their earnings distribution from the beginning of the period and the share of full-time employment at the end of the period. Conversely, $\widetilde{w}_{p}^{\prime}$ would have been the $p$-th earnings percentile if the each of the subgroups had their earnings distribution from the end of the period and the share of full-time employment at the beginning of the period.

These counterfactual percentiles are drawn in panel $(b)$ of figure A.2. The DFL decomposition then basically implies that one can decompose the change in the percent from $w_{p}$ to $w_{p}^{\prime}$ into a shift and a share part in two ways.

The first is

$$
\left(w_{p}^{\prime}-w_{p}\right)=\left(w_{p}^{\prime}-\widetilde{w}_{p}\right)+\left(\widetilde{w}_{p}-w_{p}\right)=A_{\text {share }}+A_{\text {shift }} .
$$

Here, $A_{\text {share }}$ is the part of the change in the percentile that is due to shares of each of the subgroups changing assuming their respective earnings distributions remain the same as at the beginning of the period. The part $A_{\text {shift }}$ is the remainder of the change in the percentile due to the changes in the earnings functions. The second, $B_{\text {share }}$ and $B_{\text {shift }}$, switch the order in which the changes in the shares and shifts are being evaluated. 
Daly, Hobijn, and Wiles

Table 1. CPS survey design

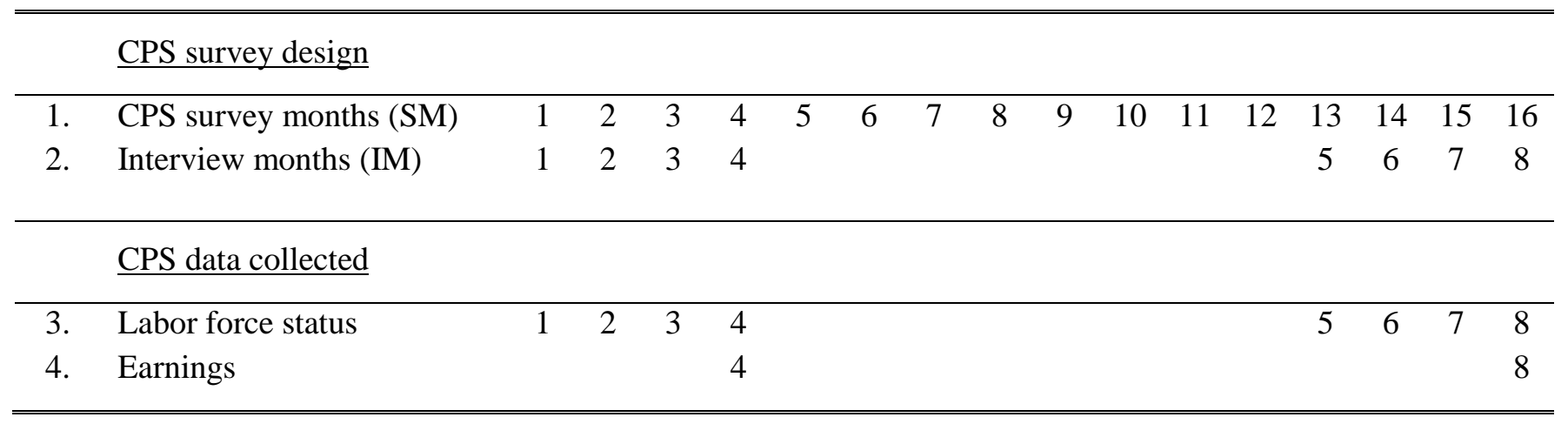


Table 2. Labor Market Status Subgroups used in the Decomposition

\begin{tabular}{|c|c|c|c|c|}
\hline I & II & III & IV & $\mathrm{V}$ \\
\hline$\underline{\text { Subgroups }}$ & \multicolumn{2}{|c|}{$\underline{\text { Labor Market Status Beginning and End of Year }}$} & \multicolumn{2}{|c|}{$\underline{\text { Share of All Wage Earners }}$} \\
\hline Name & SM4 (IM4) & SM16 (IM8) & SM4 (IM4) & SM16 (IM8) \\
\hline \multicolumn{5}{|c|}{ Full-time employed at beginning and end of year } \\
\hline 1. Same Job (SJ) & Full-time employed & Still employed in the same job & 40.8 & 40.9 \\
\hline 2. Not in Same Job (NISJ) & Full-time employed & Employed in different job & 48.4 & 48.2 \\
\hline Total & & & 89.2 & 89.1 \\
\hline \multicolumn{5}{|l|}{ Entry to/Exit from full-time employed } \\
\hline \multirow[t]{2}{*}{ 3. Part-time/self-employed (PT) } & Part-time or self-employed & Full-time employed & & 5.1 \\
\hline & Full-time employed & Part-time or self-employed & 3.9 & \\
\hline \multirow[t]{2}{*}{ 4. Unemployed } & Unemployed & Full-time employed & & 2.6 \\
\hline & Full-time employed & Unemployed & 2.7 & \\
\hline \multirow[t]{2}{*}{ 5. Not-in-labor-force (NILF) } & Not in the labor force & Full-time employed & & 3.2 \\
\hline & Full-time employed & Not in the labor force & 4.3 & \\
\hline
\end{tabular}


Table 3. Summary statistics by subgroup of full-time wage and salary earners

\begin{tabular}{llcc}
\hline \hline & & I & II \\
& & \multicolumn{2}{c}{ Share of subgroup below the median } \\
\cline { 3 - 3 } 1. Same Job & Beginning of period & End of period \\
2. Not in the Same Job & 45.4 & 43.9 \\
& & 50.1 & 48.4 \\
\cline { 3 - 4 } 3. Part Time / Self Employed & From full-time employment: & To full-time employment: \\
4. Unemployed & 76.4 & 80.7 \\
5. Not in the Labor Force & 64.0 & 72.8 \\
\hline \hline
\end{tabular}

Note: All shares reported are average shares over our 1980-2011 and are reported in percentages. 
Table 4. Decomposition of variance and cyclicality of real MWE growth: 1980-2011.

\begin{tabular}{llcc}
\hline \hline & & I & II \\
& Measure & Variance & Cyclicality \\
\hline 1. Total & 100.0 & -0.112 \\
& & & $(-1.52)$ \\
& & A. Composition Effect &
\end{tabular}

Replacement component

2. Same job $0.6 \quad 0.012$

3. Not in the same job

0.003

Exit and entry components

4. Part-time or self employed $\quad 4.1 \quad 0.063$

5. Unemployed $3.6 \quad-0.004$

6. Not in the labor force $\quad(-0.28)$

Not in the labor force $\quad 0.2 \quad 0.036$

7. Total

$8.8 \quad 0.110$

\section{B. Wage Growth Effect}

8. Same job

$41.0-0.080$

9. Not in the same job

10 Total

\begin{tabular}{cc}
50.2 & $\begin{array}{c}-0.142 \\
(-3.05)\end{array}$ \\
\hline 91.2 & -0.222
\end{tabular}

Note: Rows 2 through 10 in column I are reported in percent of the total variance reported in row 1 in squared percentage points. Totals do not add up to 100 due to rounding. Column II reports regression coefficients, $\beta$, of cyclicality regression, $\Delta \ln (w)=\alpha+\beta u+\varepsilon$, for total real MWE growth measured in percentage points and its subcomponents. $t$-values are in parentheses. 
Figure 1. Real wage growth and changes in the unemployment rate

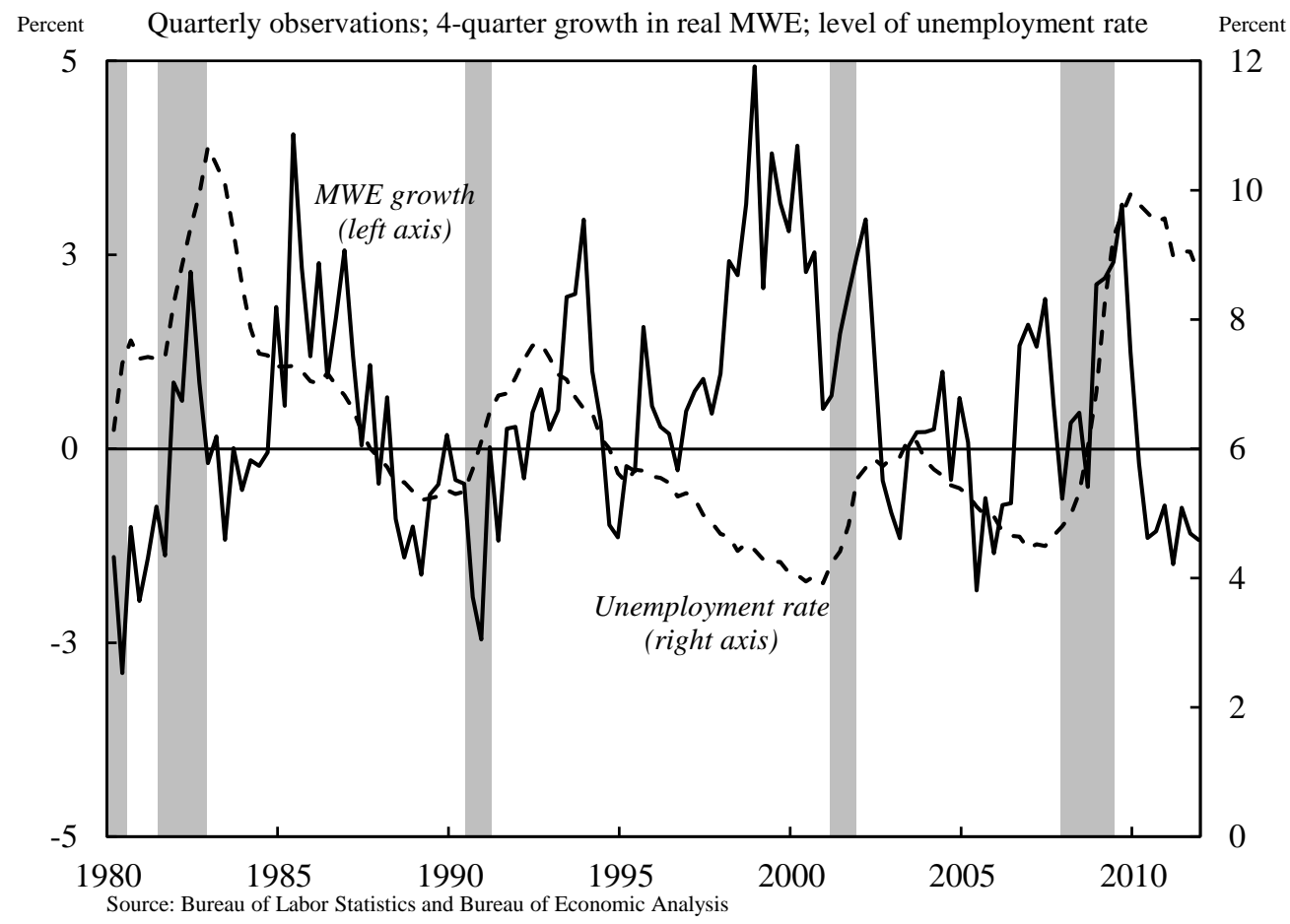

Figure 2. Four aggregate measures of real wage growth

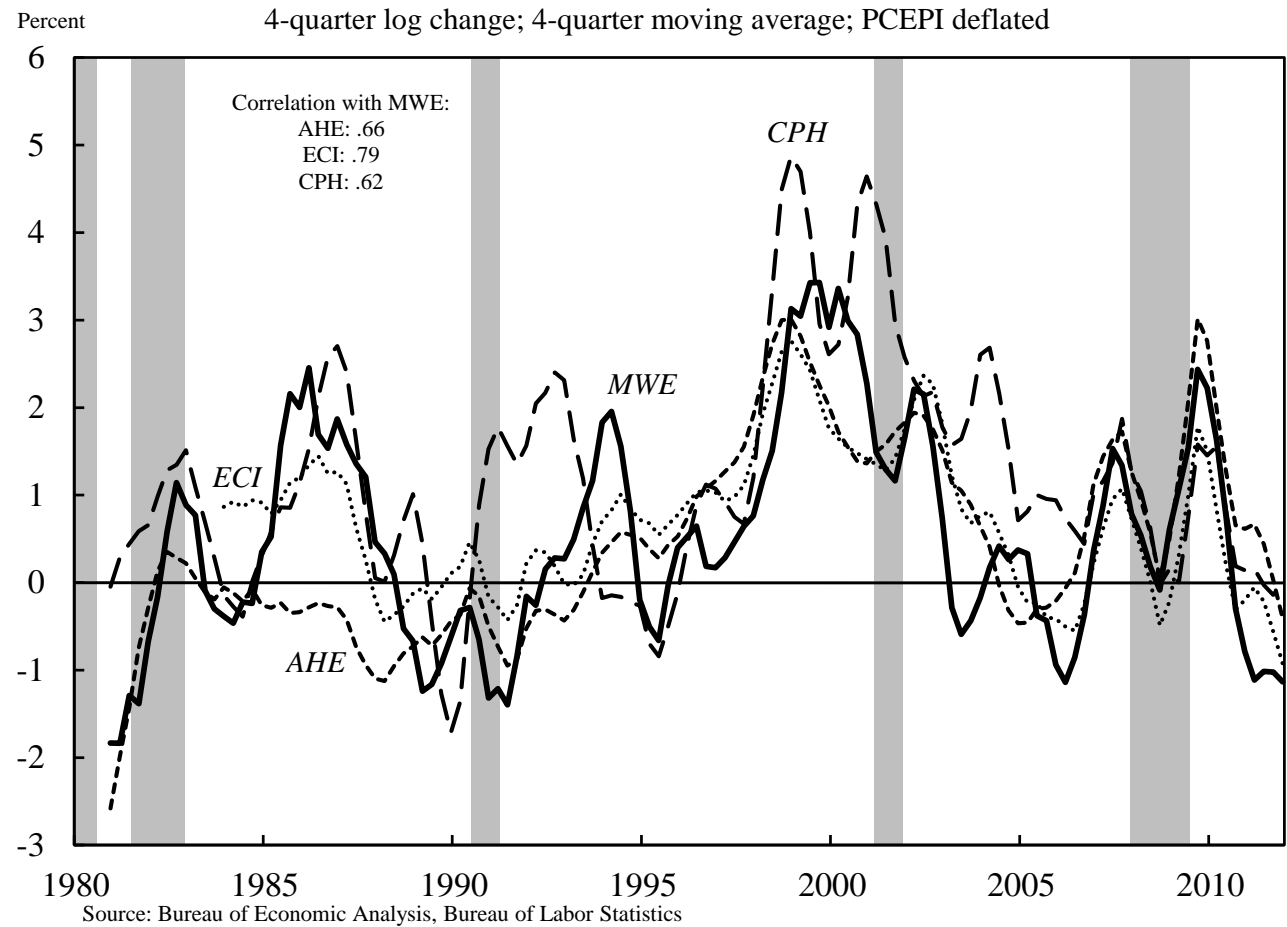


Figure 3. MWE growth for published and matched CPS samples.

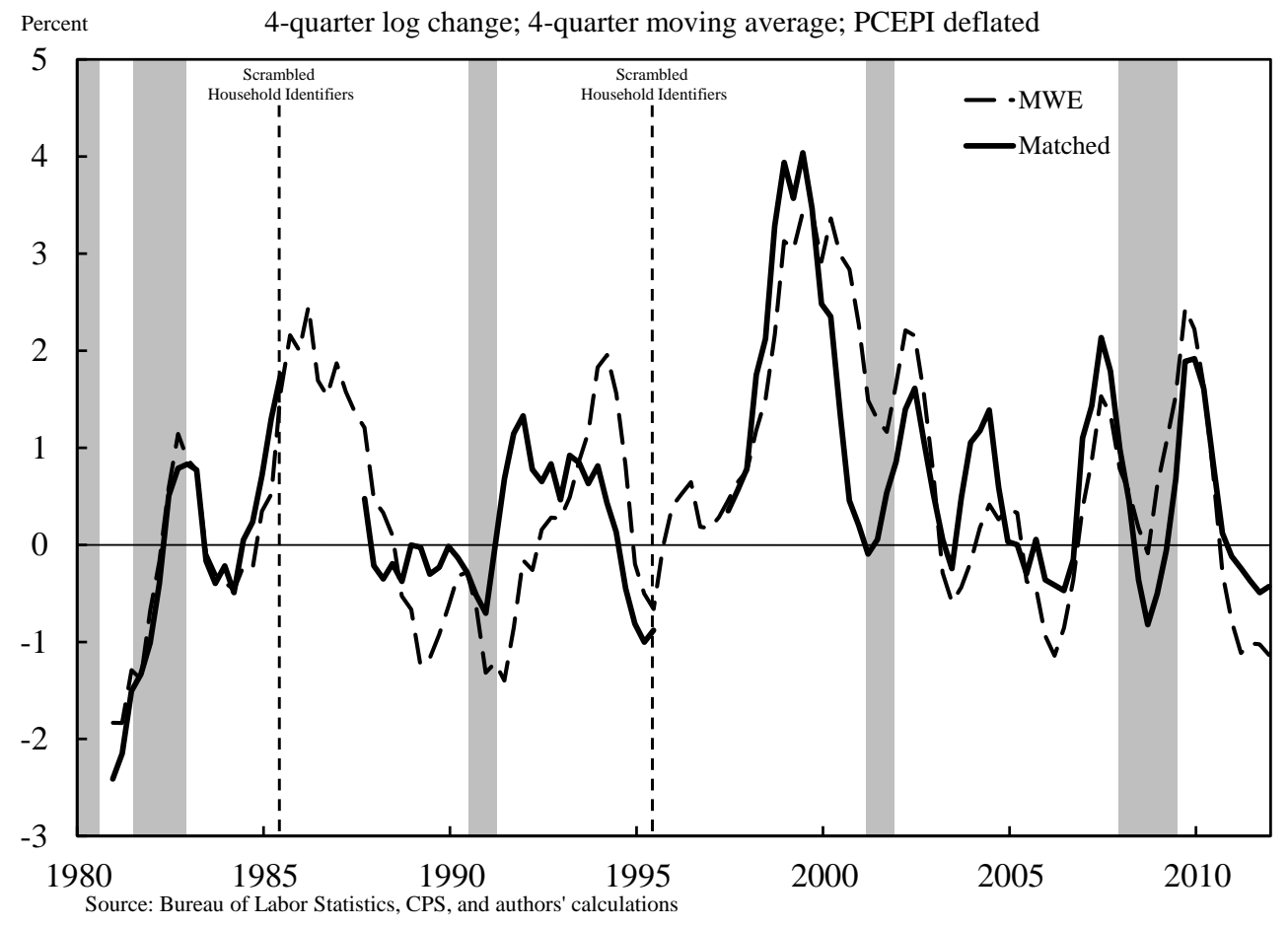


Daly, Hobijn, and Wiles

Figure 4. Graphical representation of equation (2).

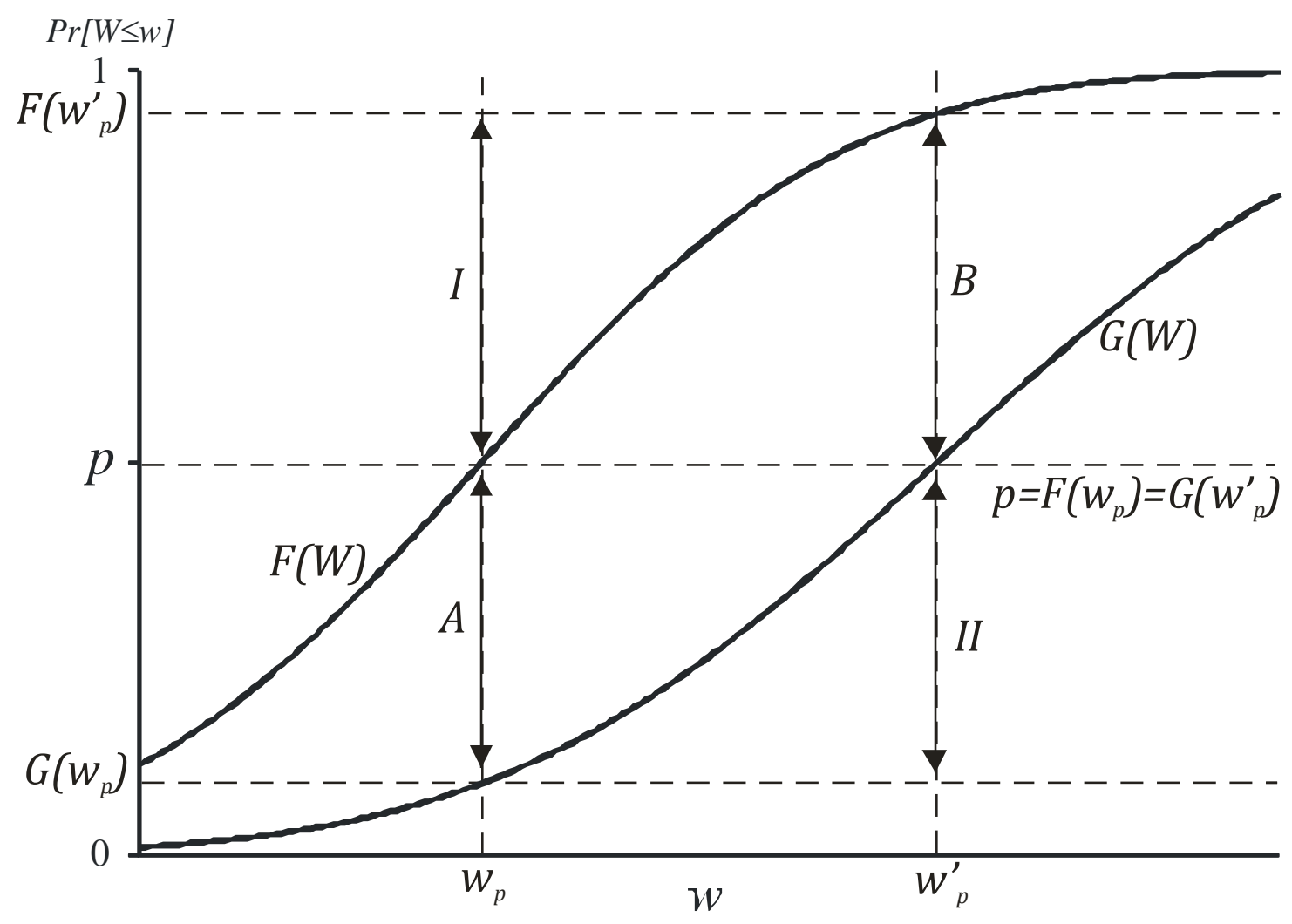


Dissecting Aggregate Real Wage Fluctuations

Figure 5. Subgroups as shares of the full-time employed.
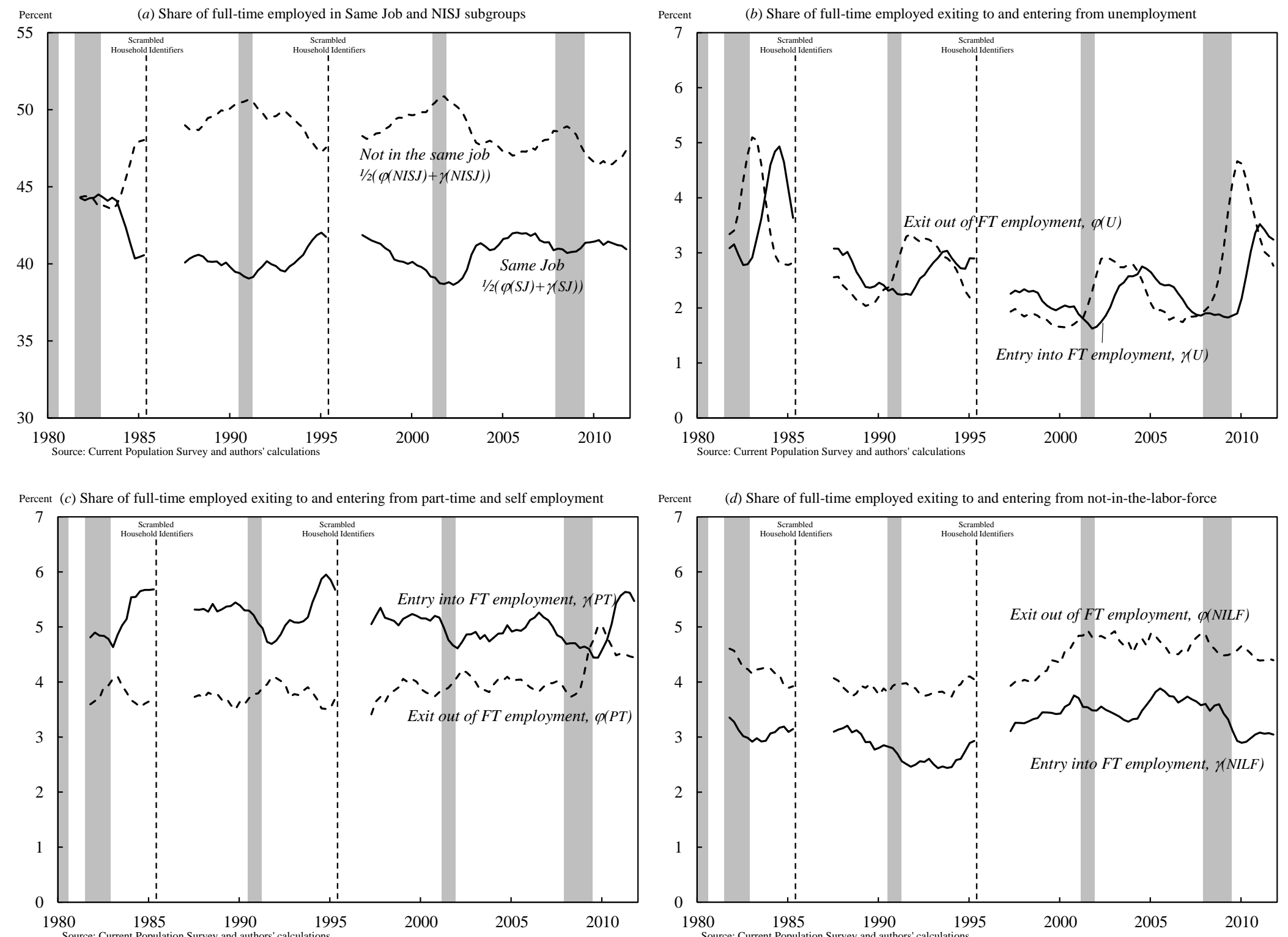

Note: All panels contain 4-quarter moving averages. Panel (a) contains the average of the shares at the beginning and end of the year. Other panels show shares indexed at end of year. 
Daly, Hobijn, and Wiles

Figure 6. Shifts in earnings distribution function at median for different subgroups.
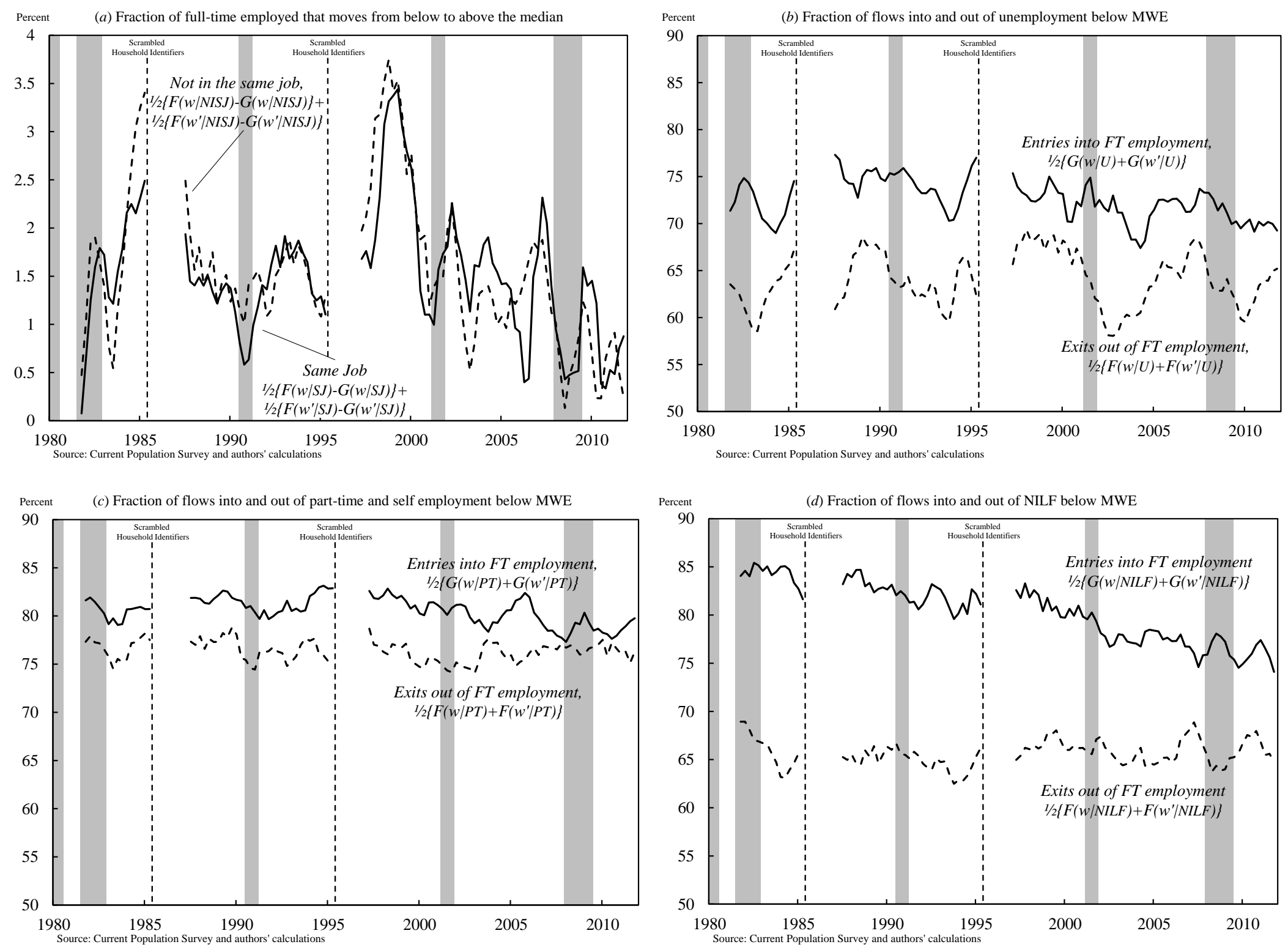

Note: All panels contain 4-quarter moving averages 
Figure 7. Decomposition of composition effect and wage growth effect by subgroup.
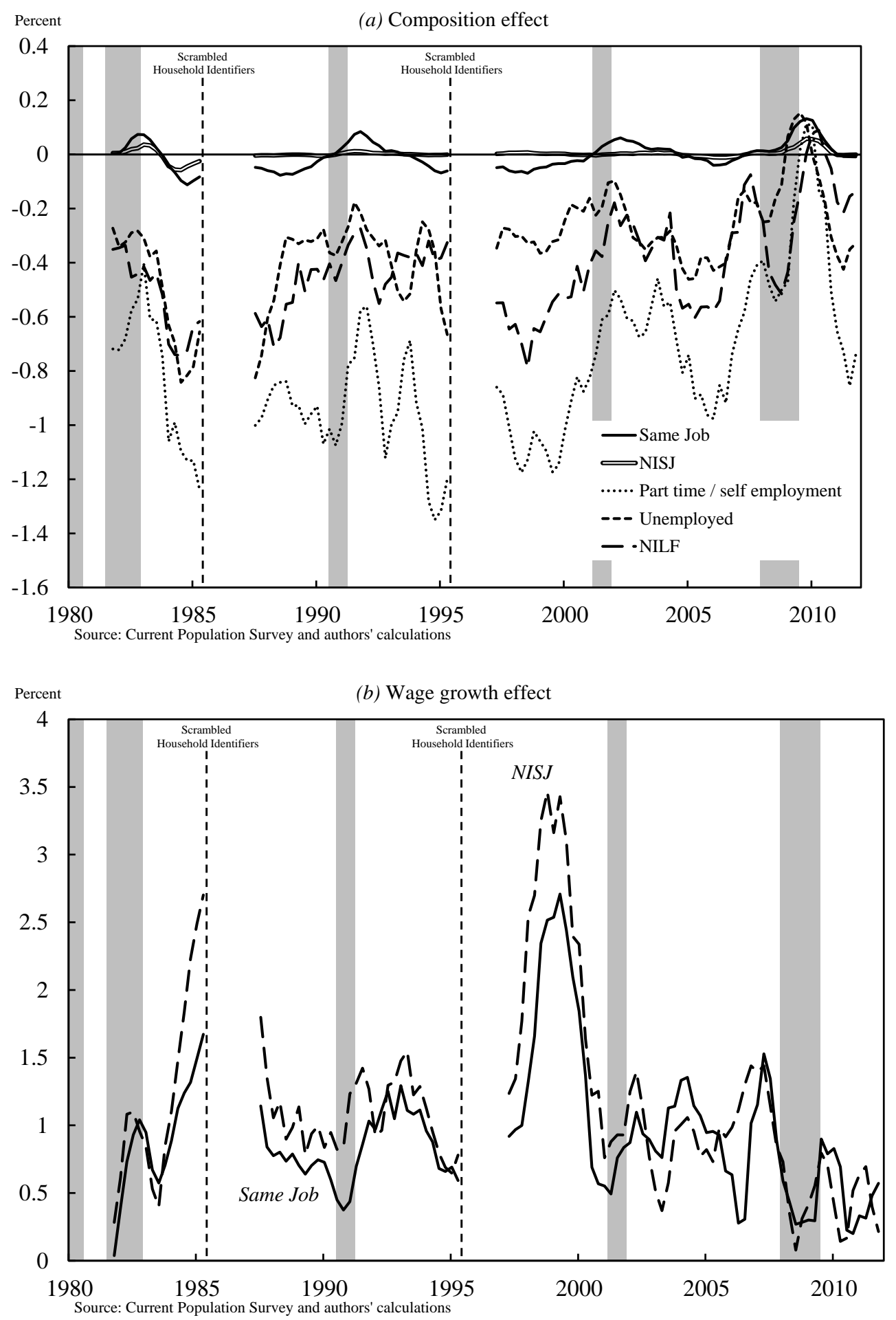

Note: All panels contain 4-quarter moving averages 
Daly, Hobijn, and Wiles

Figure 8. Contributions of changes in shares and shifts in earnings distributions to log change of MWE.

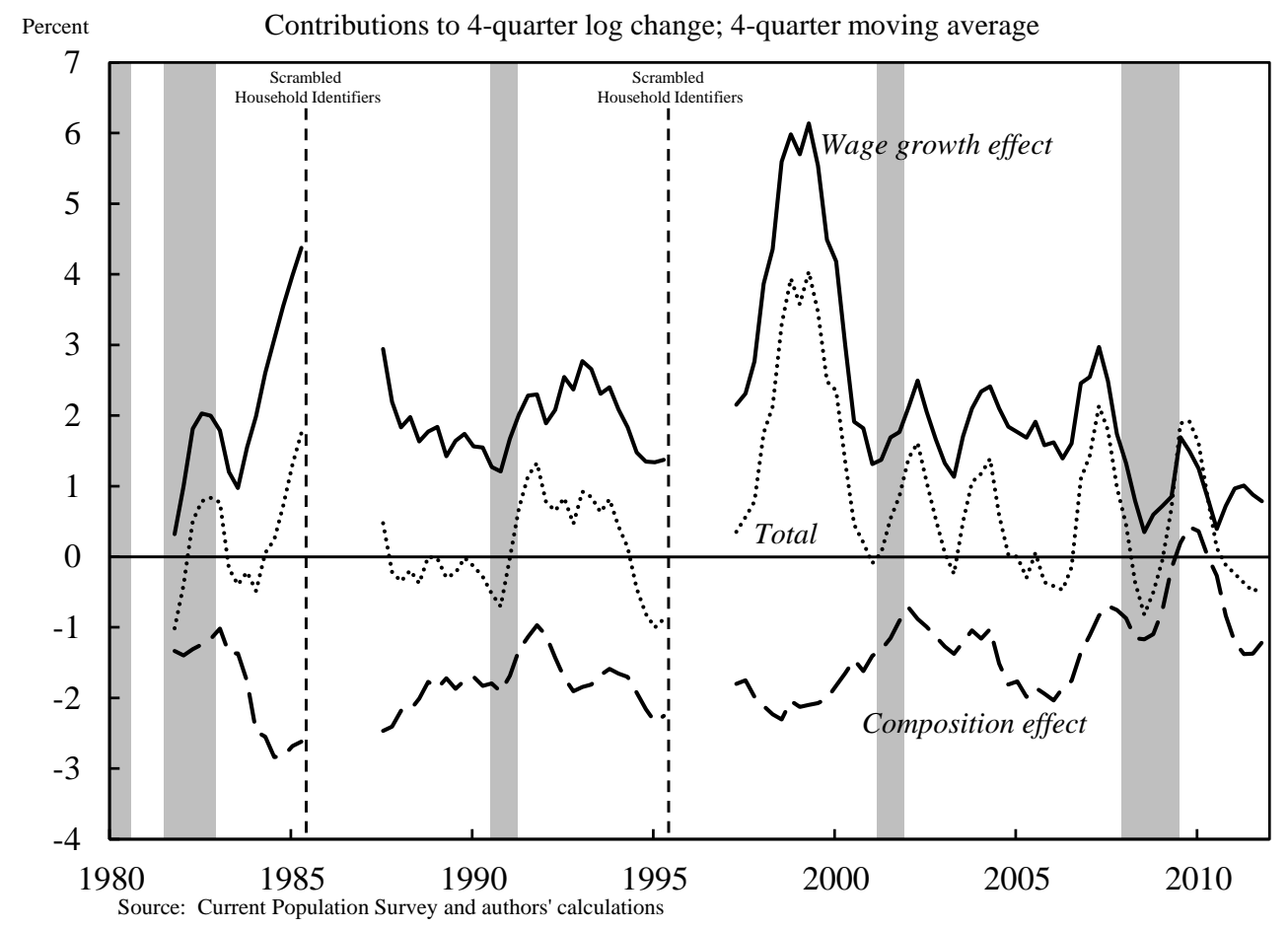


Figure A.1. Share of not-in-the-same-job imputed as job-to-job transitions.

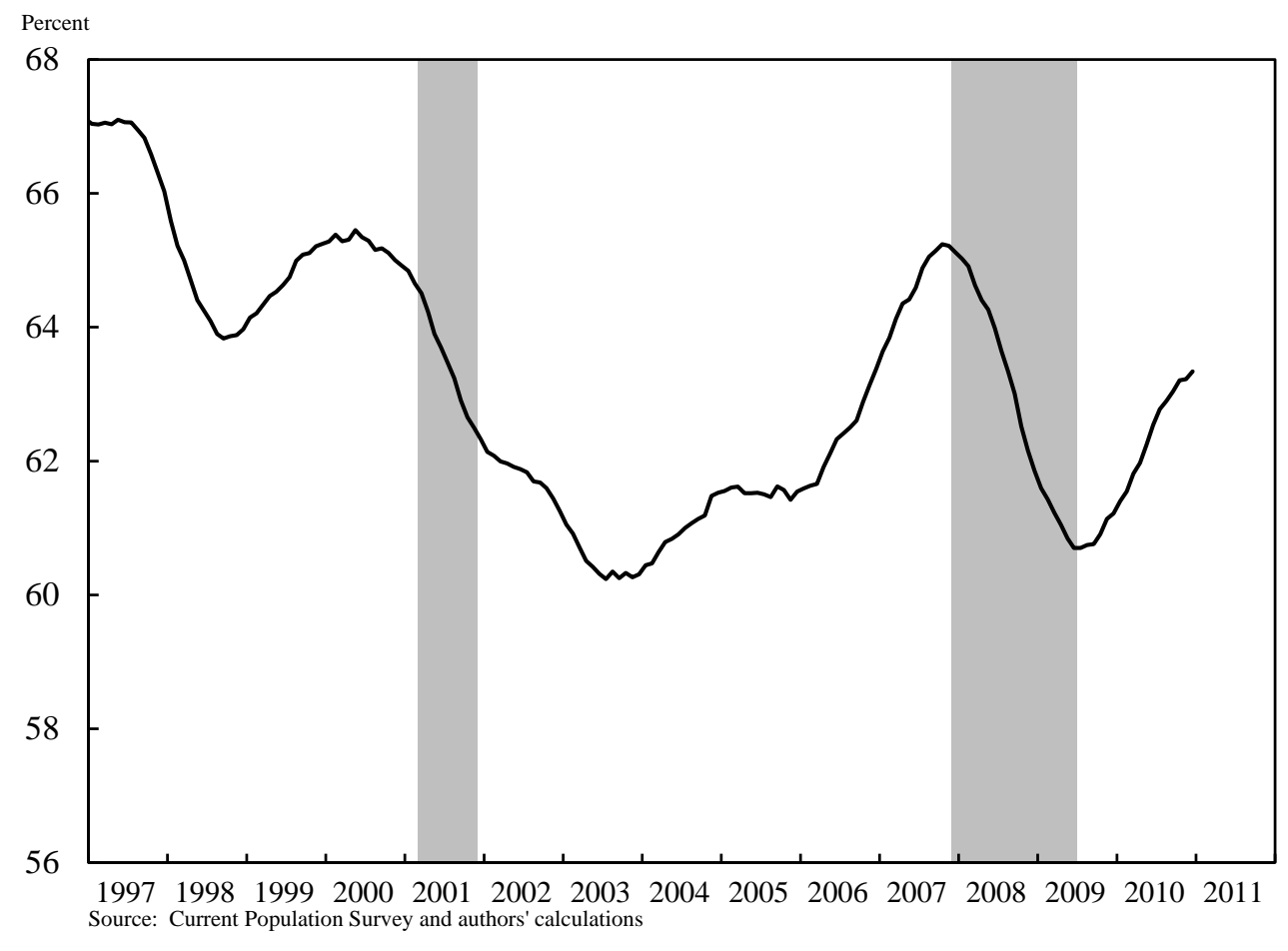

Note: 12-month moving averages 
Daly, Hobijn, and Wiles

Figure A.2. Comparison of decomposition in this paper with that in DiNardo, Fortin, and Lemieux (1996).
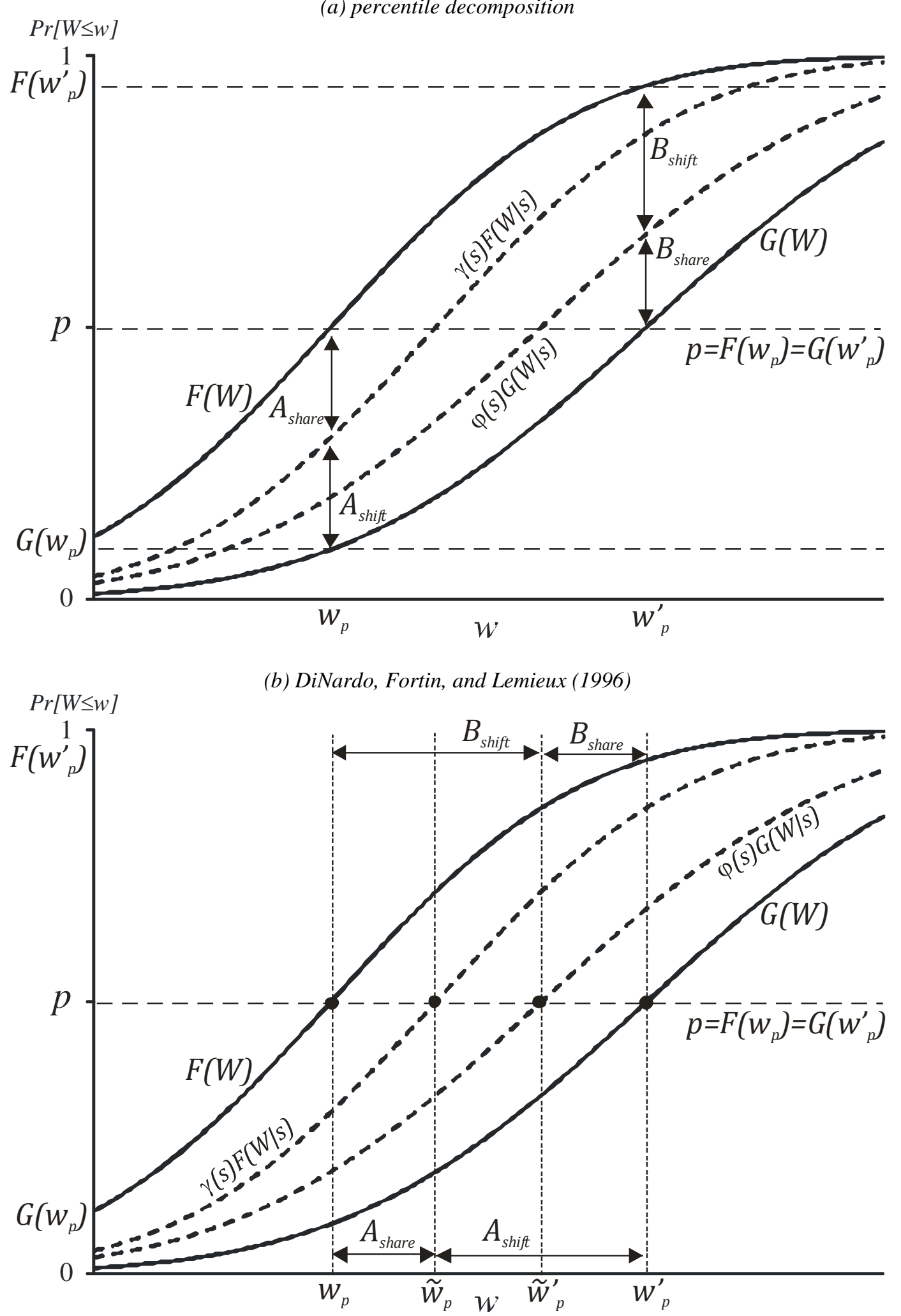